\title{
LA CONTROVERSIA SOBRE LA TITULARIDAD JURÍDICO-INTERNACIONAL DE LOS ESPACIOS MARÍTIMOS ADYACENTES A GIBRALTAR
}

\author{
Pablo Antonio Fernández SÁnchez \\ Catedrático de Derecho Internacional Público y Relaciones Internacionales \\ Universidad de Sevilla
}

SUMARIO: INTRODUCCIÓN.-1. INCIDENCIA DEL DERECHO INTERNACIONAL DE LA DESCOLONIZACIÓN EN LA TITULARIDAD DE LOS ESPACIOS MARÍTIMOS ADYACENTES A GIBRALTAR.-2. SITUACIÓN JURÍDICA DEL PUERTO DE GIBRALTAR Y SUS AGUAS INTERIORES.-3. LA APLICACIÓN DEL PRINCIPIO LEX SPECIALIS DEROGAT LEGI GENERALI.-4. LA DOCTRINA DE LA «COSTA SECA».-5. CONCLUSIONES.

\section{INTRODUCCIÓN}

El Tratado de Utrecht, de 1713, que es el que regula la presencia jurídica del Reino Unido en Gibraltar, no recogía los espacios marítimos circundantes a La Roca. Ello es así, entre otras cosas, porque en aquella época no había espacios marítimos, tal como los conocemos hoy día.

La tradicional política española es que esos espacios marítimos, en el marco de la cesión que se hace en Utrecht no son contemplados porque la voluntad era la de mantener La Roca sin jurisdicción circundante alguna, en parte por motivos relacionados con los ataques berberiscos (seguridad) en parte relacionados con el contrabando y la entrada ilegal de mercaderías (fiscalidad) y en parte también para evitar la expansión territorial del espacio que se cede forzadamente para que sea utilizado como base militar (territorialidad).

Esto lleva a España a que cuando se adhirió a los Convenios de Ginebra de 29 de abril de 1958, el 25 de febrero de 1971, formulara una declaración re- 
lativa a Gibraltar. Igualmente cuando firma y luego ratifica la Convención de las Naciones Unidas para el Derecho del Mar, hace una Declaración expresa por la que no puede interpretarse que España reconoce cualesquiera derecho o situación relativos a los espacios marítimos de Gibraltar que no estén comprendidos en el art. 10 del Tratado de Utrecht ${ }^{1}$.

Para España es una cuestión de soberanía. Es más, cuando España acepta la jurisdicción del Tribunal Internacional sobre el Derecho del Mar, hace una Declaración, después de haber ratificado la Convención de Naciones Unidas sobre el Derecho del Mar el 4 de diciembre de 1984, excluyendo de la jurisdicción de dicho Tribunal la delimitación de las zonas marítimas, o las relativas a bahías o títulos históricos, pensando exclusivamente en el caso de la Bahía de Algeciras ${ }^{2}$.

Ahora bien, la realidad práctica es que, mientras jurídicamente España reivindica la ausencia de espacios marítimos en Gibraltar, con excepción de

1 «El Gobierno español, en el momento de proceder a la firma de la presente Convención, declara que este acto no puede ser interpretado como reconocimiento de cualesquiera derechos o situaciones relativas a los espacios marítimos de Gibraltar que no estén comprendidos en el art. 10 del Tratado de Utrecht, de 13 de julio de 1713, entre las Coronas de España y Gran Bretaña». El texto inglés es el siguiente: «The Spanish Government, upon signing this Convention, declares that this act cannot be interpreted as recognition of any rights or situations relating to the maritime spaces of Gibraltar which are not included in article 10 of the Treaty of Utrecht of 13 July 1713 between the Spanish and British Crowns. The Spanish Government also considers that Resolution III of the Third United Nations Conference on the Law of the Sea is not applicable in the case of the Colony of Gibraltar, which is undergoing a decolonization process in which only the relevant resolutions adopted by the United Nations General Assembly apply» (United Nations, Treaty Series, vol. 1833, p. 3). Por su parte, el Reino Unido hizo la siguiente Declaración: «Con respecto al punto 2 de la declaración hecha al ratificar la Convención por el Gobierno de España, el Gobierno del Reino Unido no tiene ninguna duda acerca de la soberanía del Reino Unido sobre Gibraltar, incluidas sus aguas territoriales. El Gobierno del Reino Unido, como autoridad administradora de Gibraltar, hace extensible la adhesión del Reino Unido al convenio y la ratificación del convenio a Gibraltar. El Gobierno del Reino Unido, por tanto, rechaza el punto 2 de la declaración española por carecer de fundamento». El texto inglés es el siguiente: "With regard to point 2 of the declaration made upon ratification of the Convention by the Government of Spain, the Government of the United Kingdom has no doubt about the sovereignty of the United Kingdom over Gibraltar, including its territorial waters. The Government of the United Kingdom, as the administering authority of Gibraltar, has extended the United Kingdom's accession to the Convention and ratification of the Agreement to Gibraltar. The Government of the United Kingdom, therefore, rejects as unfounded point 2 of the Spanish declaration" (http:// www.un.org/Depts/los/convention_agreements/convention_declarations.htm\#UK\%20Upon\%20accession). Para un análisis de estas Declaraciones, véase Riouelme CoRTADo, R., España ante la Convención sobre el Derecho del Mar. Las Declaraciones formuladas, Murcia, Universidad de Murcia, 1990. Igualmente Hierrezuelo Conde, G., La postura española en la Tercera Conferencia de las Naciones Unidas sobre el Derecho del Mar con respecto al Mar Territorial, Enciclopedia Virtual, eumed.net, especialmente cap. II.9, pp. 225 y ss. (http://www.eumed.net/librios-gratis/2015/1432/i9ndez.htm).

2 Declaración hecha después de la ratificación de la Convención de Naciones Unidas sobre el Derecho del Mar, el 19 de julio de 2002: «El Gobierno de España declara que, de conformidad con lo dispuesto en el párr. 1.a) del art. 298 de la Convención, no acepta los procedimientos previstos en la Sección 2. ${ }^{a}$ de la Parte XV para la solución de las controversias relativas a la interpretación o la aplicación de los arts. 15, 74 y 83 concernientes a la delimitación de las zonas marítimas o las relativas a bahías o títulos históricos» (BOE núm. 170, de 17 de julio de 2003). El texto oficial en inglés es el siguiente: "The Government of Spain declares, pursuant to the provisions of article 298, para. 1(a) of the Convention, that it does not accept the procedures provided for in part $X V$, section 2, with respect to the settlement of disputes concerning the interpretation or application of articles 15, 74 and 83 relating to sea boundary delimitations, or those involving historic bays or titles». 
las aguas interiores del Puerto de Gibraltar, el comportamiento español es de tolerancia y de adjudicación de jurisdicción sobre las aguas próximas a Gibraltar, hasta la equidistancia dentro de la Bahía de Algeciras, con el mar territorial español.

España, cuando delimita sus espacios marítimos, no encierra las aguas de la Bahía de Algeciras como aguas interiores y, por tanto, genera mar territorial, pero dirige el tráfico de entrada y salida al Puerto de Algeciras, teniendo en cuenta la mediana imaginaria que separaría las aguas de Gibraltar, acepta que sea fondeadero de buques autorizado por las autoridades del Peñón, admite la entrada y salida de buques con destino o salida a/o de Gibraltar, aunque sean barcos cazatesoros, acepta que haya áreas de pesca controladas por la policía gibraltareña y admite la jurisdicción británica respecto a las acciones a tomar para evitar los daños ambientales, tal como se ha podido comprobar con el caso del New Flame ${ }^{3}$.

Esto nos permitiría afirmar que hay una cierta esquizofrenia porque, por un lado, España no acepta la proyección de espacios marítimos sobre la Bahía de Algeciras y reivindica que la vigencia del Tratado de Utrecht le favorece en sus reclamaciones de soberanía. Sin embargo, por otro lado, la realidad práctica y, probablemente para evitar males mayores ${ }^{4}$, le hace tener un comportamiento como si aceptara la proyección de ese mar territorial de Gibraltar.

Por otro lado, el Reino Unido sólo reivindica tres millas de mar territorial fuera de la Bahía de Algeciras, hacia oriente, mientras que en la Bahía reivindica hasta la mediana. ¿Por qué no reivindica más mar territorial u otros espacios marítimos?

¿Significa esta esquizofrenia una dejación de derechos o un modus vivendi que permita evitar tensiones que pudieran agravar la situación hasta el indeseado e ilegal uso de la fuerza?

Por otro lado, hay que considerar que la aplicación del Derecho internacional, teniendo en cuenta exclusivamente la Convención de Naciones Unidas sobre el Derecho del Mar (que es la teoría «mantra» de los que consideran al Tratado de Utrecht como otro «mantra $»^{5}$ ), es, sencillamente simplista y el Derecho, especialmente el Derecho internacional, requiere para su interpretación y aplicación de un método sistémico que permita deducir el Derecho aplicable.

Por tanto, me propongo poner de manifiesto las tesis y antítesis planteadas en el marco de los espacios marítimos adyacentes a Gibraltar ${ }^{6}$, en el marco de

\footnotetext{
3 Zamora Roselló, M. R., Los incidentes marítimos en el Atlántico Europeo y su influencia en la evolución del derecho de la seguridad marítima, Madrid, IUEM, 2008. También MAGONE, J. M., Contemporary Spanish Politics, Nueva York, 2. ${ }^{\text {e }}$ ed., Routledge, 2009, p. 413.

4 Así lo reconoció el Ministro español de Defensa, Sr. García Vargas, en 1992. Véase su declaración en Spanish Yearbook of International Law, 1992, p. 174.

5 Verdú BAEZA, J., «La controversia sobre las aguas de Gibraltar: el mito de la costa seca», Revista Española de Derecho Internacional, vol. LXVI-1, 2014, pp. 81-123, véase especialmente p. 121.

6 Esta controversia ha sido señalado por numerosos autores, entre ellos IzouIERdo SANZ, C., Gibraltar en la Unión Europea, Madrid, Tecnos, 1996, pp. 42-46; igualmente AnTón GuARdiola, C., Gibraltar:
} 
su contexto global que permita bien afirmar las posiciones jurídicas que puedan establecerse o bien denunciar las prácticas contrarias a las propias posiciones jurídicas o establecer acuerdos que puedan conformar una síntesis que permita desarrollar una política protectora de todos los intereses en juego.

Soy también consciente que la complejidad del problema abarca igualmente una distinción entre las aguas proyectadas por el Istmo ${ }^{7}$, espacio ocupado de forma ilegal por el Reino Unido y sobre el que España siempre ha sido objetor persistente, por lo que el Reino Unido no puede utilizar la doctrina de la prescripción adquisitiva. En este sentido la posición española queda clara al respecto, con la siguiente declaración:

«...España, que cedió Gibraltar en el art. X del Tratado de Utrecht, no ha cedido nunca ninguna parte del Istmo. La instalación británica en el Istmo nunca lo ha sido a título de soberanía y España siempre ha protestado, formal o materialmente, contra esa presencia. Si sus protestas no han tenido efectividad se debe a una pura y simple situación de fuerza que no puede admitirse en Derecho. Dicha presencia británica viene determinada por hechos consumados. Pretender ahora que ninguna distinción se puede establecer entre él y el resto de la colonia es querer asimilar la propiedad adquirida mediante título a una mera anexión ilegal» ${ }^{8}$.

En todo caso, mi reflexión es de carácter general sobre las aguas adyacentes, sin entrar en esta delimitación en la zona del Istmo. Tampoco será objeto de estudio la necesaria cooperación transfronteriza en materia marítima porque este tema plantea numerosas aristas que tienen que ver con el problema de la titularidad ${ }^{9}$. Por tanto, voy a dedicarme al tema de la titularidad jurídica y dejar para otro estudio esa necesidad de cooperar para resolver problemas comunes, de interés para todas las partes implicadas.

\section{INCIDENCIA DEL DERECHO INTERNACIONAL DE LA DESCOLONIZACIÓN EN LA TITULARIDAD DE LOS ESPACIOS MARÍTIMOS ADYACENTES A GIBRALTAR}

Los espacios marítimos adyacentes a Gibraltar no surgen de forma autónoma al problema de la situación de esta colonia. Deben ser analizados en el

un desafío en la Unión Europea, Valencia, Tirant lo Blanch, 2011, que se ocupa de los límites marinos de la cesión en las pp. 45-55.

7 Sobre este tema, véase GonZÁlez García, I., «Los espacios marítimos del istmo y Peñón de Gibraltar, cuestiones en torno a su delimitación», en Sobrino HerediA, J. M. (coord.), Mares y océanos en un mundo en cambio: tendencias jurídicas, actores y factores, Valencia, Tirant lo Blanch, 2007, pp. 141-170.

${ }^{8}$ Véase El Libro Rojo sobre Gibraltar, Documentos sobre Gibraltar presentados a las Cortes Españolas por el Ministro de Asuntos Exteriores, Madrid, Ministerio de Asuntos Exteriores, 1967, p. 87.

9 Sobre estas cuestiones, los trabajos de investigación han sido mucho más prolíficos y daré cuenta de ello en otro trabajo diferente a éste. No obstante, véase, por ejemplo, VALLE GálVEZ, A. del, GonzÁLEZ García, I. y Verdú BAEZA, J., «Propuestas para un acuerdo práctico sobre las aguas de Gibraltar», en Cardona Llorens, J. M., Pueyo losa, J., Rodríguez-Villasante Prieto, J. L. y Sobrino Heredia, J. M. (eds.); AzNAR Gómez, J. M. (coord.), Estudios de Derecho internacional y Derecho europeo en homenaje al profesor Manuel Pérez González, Valencia, Tirant lo Blanch, 2012, pp. 407-440. 
contexto colonial. Por tanto, no pueden entenderse exclusivamente teniendo en cuenta el Derecho del Mar.

Gibraltar no posee una frontera política definida exactamente. El único documento jurídico que reconoce esta posibilidad es el Tratado de Utrecht de 13 de junio de 1713, donde hay una cesión de propiedad a la Corona británica de la ciudad y castillo de Gibraltar, juntamente con su puerto y fortaleza, sin jurisdicción alguna territorial y sin comunicación alguna abierta con el país circunvecino por parte de tierra ${ }^{10}$. No es exactamente un Tratado de Límites pero sí un Tratado de Cesión de un territorio.

La terminología antigua que utiliza y la cláusula de retrocesión, no comparable con los conceptos actuales de soberanía, jurisdicción y reintegración territorial han supuesto históricamente una controversia sobre el territorio.

Sin embargo, la existencia del Derecho intertemporal hace incompatible la adquisición de territorios ${ }^{11}$ de esta forma tan anómala como fue la cesión forzada, no por derecho de conquista sino por la ocupación de 1703 en nombre de un aspirante al trono español. La Carta de las Naciones Unidas y su doctrina sobre la descolonización han supuesto una nueva regulación jurídica que descarta aspectos como la soberanía británica sobre el territorio (sólo es admisible la Administración temporal del territorio) o la independencia (se apuesta por la integración territorial).

Esta controversia se halla inscrita ante el Comité de Descolonización de la Asamblea General de las Naciones Unidas, llamado el Comité de los Veinticuatro. Y esta controversia sobre el territorio gibraltareño hace que hoy día exista una Potencia administradora del territorio: Reino Unido, y una potencia reclamante: Reino de España.

Esta situación jurídica de la colonia está bastante clara y es pacífica en términos jurídicos. Hay títulos jurídicos que avalan la presencia del Reino Unido en Gibraltar (Tratado de Utrecht) y hay títulos jurídicos que avalan la reclamación española (reintegración territorial por aplicación del Principio de Descolonización, que le reconoce la ONU y el propio Tratado de Utrecht, que España también invoca, donde no cabe más que la retrocesión a España).

No hay que olvidar que la aplicación del principio de descolonización no implica aceptar la voluntad de los habitantes de un territorio, sobre todo si no se trata de un pueblo colonizado. Recordemos la retrocesión que hizo España de Ifni a Marruecos, por el Acuerdo de Fez de 4 de enero de 1969 ${ }^{12}$, de

10 Ministerio de Asuntos Exteriores, La Cuestión de Gibraltar, Madrid, 2008, pp. 101-102.

11 Gros Espiell, H., «El Derecho Intertemporal y las formas de adquisición del territorio en el Derecho Internacional Contemporáneo", Jurídica. Anuario del Departamento de Derecho de la Universidad Iberoamericana, 1982, núm. 14, p. 147.

12 Montoro, G., "La retrocesión de Tarfaya e Ifni», Espacio, Tiempo y Forma, S. V. H. ${ }^{a}$ Contemporánea, t. IV, 1991, pp. 181-190, especialmente p. 189. Véase el documento en http://e-spacio.uned.es/ fez/eserv/bibliuned:ETFSerie5-52443BCD-A82D-F222-B004-9FE7EFDD302D/Documento.pdf. Se habla de retrocesión porque Ifni había sido cedido por Marruecos en el Tratado de Tetuán de 1860. Véase 
conformidad con la Resolución de la Asamblea General de Naciones Unidas núm. 2428 de 18 de diciembre de $1968^{13}$.

De esta forma, esta retrocesión contribuyó con esta acción a una interpretación extensiva del citado principio, que asumiría la Asamblea General de las Naciones Unidas desautorizando el referéndum llevado a cabo en Gibral$\operatorname{tar}^{14}$, confirmándose en el caso de Portugal retrocediendo Goa a India ${ }^{15}$, y más recientemente reconfirmándose en el caso Reino Unido a China respecto a Hong-Kong, en $1997^{16}$ y en el caso de Portugal a China, en relación con Macao, en $1999^{17}$.

Estos ejemplos son señalados por Víctor M. Sánchez como ejemplos de retrocesión que pueden servir de ejemplos a los casos de Gibraltar y Malvinas ${ }^{18}$.

Los gibraltareños actuales que habitan la colonia, a quienes podríamos llamar gibraltareños del sur, son los descendientes del pueblo colonizador o de las personas autorizadas a instalarse en dicho territorio por las autoridades coloniales ${ }^{19}$. Los gibraltareños originarios serían los descendientes de los gibraltareños que en 1713 abandonaron, provisionalmente, la ciudad, asentándose en su Campo, a quienes podríamos llamar gibraltareños del norte. Por tanto, «en Gibraltar no existe un pueblo con unas características políticas, sociales, culturales, religiosas y étnicas propias, sino que se trata, como en otros supuestos de colonialismo británico - piénsese, por ejemplo, en las Malvinas-, de una población importada tras la expulsión de los antiguos moradores de la Roca. No existe, por tanto, un pueblo sometido a la dominación colonial, sino una población establecida en la Roca bajo la cobertura británica» ${ }^{20}$.

GonZÁlez CAMpos, J. D., «Las pretensiones de Marruecos sobre los territorios españoles en el Norte de África, 1956-2002», en Verdú BAeZA, J. (ed.), España y Marruecos, en el centenario de la Conferencia de Algeciras, Madrid, Dykinson, 2007, pp. 81-82.

13 Este tema sirvió para elaborar la doctrina de Naciones Unidas sobre la descolonización. Véase DE PINIÉs y Rubio, J., La descolonización española en las Naciones Unidas. Guinea Ecuatorial (Fernando Poo y Río Muni), Ifni, Sahara Occidental, Gibraltar y las Naciones Unidas, Madrid, Centro de Estudios Políticos y Constitucionales, 2001, especialmente p. 60.

14 Resolución 2353 (XXII) de 19 de diciembre de 1967.

15 Aunque Goa fue invadida por India en 1961, Portugal, tras la Revolución de los Claveles, en 1974 aceptó la retroacción de Goa a India.

16 Véase Tsang, S., A Modern History of Hong-Kong, I. B. Nueva York, Tauris, 2007, pp. 228 y ss.

17 El 20 de diciembre de 1999, China y Portugal firmaron una Declaración por la que se retrotraía Macao a la República Popular de China. Véanse detalles en FERnÁndez Lommen, Y., China: La Construcción de un Estado Moderno, Madrid, Catarata, 2001, p. 150.

18 SÁnchez, V. M. (dir.), Derecho Internacional Público, Barcelona, 2. a ed., Huygen Editorial, 2010, p. 211.

19 El reparto poblacional de los habitantes de Gibraltar, tras el Tratado de Utrecht en 1713 puede consultarse en Álvarez Cañas, M. L., Corregidores y Alcaldes Mayores: la Administración territorial andaluza en el siglo XVIII, Alicante, Publicaciones de la Universidad de Alicante, 2012, p. 56. Esto sirvió de base para aclarar, en Naciones Unidas, cómo la población actual de Gibraltar no era la autóctona. Véase Ministerio de Asuntos Exteriores, Negociaciones sobre Gibraltar, Madrid, Ministerio de Asuntos Exteriores, 1967, p. 747.

${ }^{20}$ Orinuela Calatayud, E., España y la delimitación de sus espacios marinos, Murcia, Universidad de Murcia, 1989, pp. 30-31. 
La Comisión Política Especial y de Descolonización de la Asamblea General de las Naciones Unidas ha tenido numerosísimas ocasiones de recordar la doctrina de las Naciones Unidas en este sentido. Para ello utilizó el preámbulo mismo de las Resolución 2353(XXII) de la Asamblea General que desautoriza el referéndum de Gibraltar cuando dice «que toda situación colonial que destruye total o parcialmente la unidad nacional y la integridad territorial de un país es incompatible con los propósitos y principios de la Carta de las Naciones Unidas» que no es más que un fiel reflejo del contenido de la llamada Carta Magna de la Descolonización [Resolución 1514 (XV) de 14 de diciembre de 1960] ${ }^{21}$.

Si esto es así, ¿se pueden atribuir nuevos espacios para que sean administrados por una Administración Colonial?

Si estamos ante una norma de Derecho imperativo, es decir no derogable por la voluntad de las partes, ${ }^{22}$ como es la que garantiza la autodeterminación de los pueblos y la descolonización de los territorios sometidos a dominación colonial ${ }^{23}$, en la auténtica interpretación que hacen los Estados y los tribunales internacionales, no debería caber la menor duda de que no es posible atribuir más espacios de administración a la potencia colonial porque lo que debe hacer esa potencia colonial es entregar el territorio colonizado e integrarlo territorialmente, en este caso a España.

Esperanza Orihuela considera que hay que diferenciar cuándo es un pueblo sometido a dominación colonial, que sí tendría derecho a los recursos naturales de la colonia, y por tanto a los espacios marítimos, y cuándo es un territorio sometido a dominación colonial, que no lo tendría. Éste sería el caso de Gibraltar ${ }^{24}$. Ésta es un interesante teoría que necesariamente ha de tenerse en cuenta a la hora del análisis sistémico que pretendo.

Por tanto, en principio, la regla aplicable a los espacios marítimos debe ser la misma que la de los espacios terrestres, que es la devolución, tal como exige el Derecho internacional.

Ahora bien, los espacios marítimos, acorde con una interpretación razonable (aunque siempre caben otras, obviamente), necesitan, por un lado, administración pero, por otro lado, cooperación. Ese es el planteamiento que, en mi opinión, recogía la Resolución III de la Tercera Conferencia de las Naciones Unidas sobre el Derecho del Mar, cuando declaró que:

«b) En el caso de una controversia entre Estados relativa a la soberanía sobre un territorio al que sea aplicable la presente resolución y respecto del cual

21 Así fue llamada por Miaja de la Muela por primera vez y así se ha seguido llamando desde entonces. Véase Miaja de la Muela, A., La Emancipación de los Pueblos Coloniales y el Derecho Internacional, Madrid, 2. 'ed., Tecnos, 1968, p. 6.

22 Drnas De Clément, Z., "Las normas imperativas de Derecho Internacional General (IUS COGENS). Dimensión sustancial», Academia Nacional de Derecho y Ciencias Sociales de Córdoba, Argentina, p. 1 (http://www.acaderc.org.ar/doctrina/articulos/artiuscogens).

${ }_{23}$ Domestici-Met, M. J. et al., Geopolítica y ayuda humanitaria, vol. 5, Bilbao, Universidad de Deusto, 1999 , nota 64 , p. 56 .

${ }^{24}$ Véase Orihuela Calatayud, E., España y la delimitación..., op. cit., nota 20, pp. 28 y ss. 
las Naciones Unidas hayan recomendado determinados medios de solución, las partes en esa controversia celebrarán consultas acerca del ejercicio de los derechos a que hace referencia el apartado a). En esas consultas, los intereses del pueblo del territorio de que se trate constituirán una consideración fundamental. Esos derechos se ejercerán teniendo en cuenta las resoluciones pertinentes de las Naciones Unidas y sin perjuicio de la posición de ninguna de las partes en la controversia. Los Estados interesados harán todo lo posible por concertar arreglos provisionales de carácter práctico y no pondrán en peligro ni dificultarán el logro de una solución definitiva de la controversia» ${ }^{25}$.

España se opuso a esta Resolución III, sobre todo al párrafo segundo de la misma. Igualmente hizo Argentina para dejar claro que las únicas normas aplicables a Malvinas (igual que a Gibraltar) son las pertinentes Resoluciones de la Asamblea General sobre descolonización ${ }^{26}$. En este sentido, «el que Gibraltar sea calificado como territorio no autónomo hace imposible que Gran Bretaña ejerza los derechos reconocidos en la Convención, y de otro, la existencia de una controversia entre España y el Reino Unido respecto de la soberanía, en relación con la que la Asamblea General de Naciones Unidas en su Resolución 2070 (XX), de 16 de diciembre de 1965, ha invitado a los Estados a negociar, hace depender el ejercicio de estos derechos de un acuerdo entre las partes que no se ha producido» ${ }^{27}$.

En todo caso, en mi opinión, no era necesario porque puede deducirse claramente del propio texto, que el Derecho aplicable sería el particular en cada caso. La soberanía está clara, porque debe procederse a una retrocesión de Gibraltar a España (y se supone que sin dilación). En el caso de los espacios marítimos debe haber sólo acuerdos de modus vivendi para administrar adecuadamente los problemas que se suscitan.

En temas de soberanía, la administración debe ser gestionada por el Estado que tenga atribuida la soberanía. En ningún caso, el Reino Unido tiene atribuida la soberanía, más allá del Tratado de Utrecht, dado que, a estos efectos, el Tratado de Utrecht, hoy, sólo explica y justifica la presencia del Reino Unido como potencia administradora de un territorio colonial. A los efectos de transmisión de soberanía sería un Tratado nulo por ser contrario a una norma de carácter imperativo del Derecho internacional, como es la descolonización de los territorios no autónomos, como es el caso de Gibraltar y para el que la Organización de las Naciones Unidas tiene una doctrina clara, que viene sosteniendo reiteradamente desde $1965^{28}$ hasta la actualidad ${ }^{29}$, manifestando insistentemente en la integración del territorio a España y a la obligación del Reino Unido y de España de negociar de buena fe dicha

25 http://www.un.org/depts/los/convention_agreements/texts/acta_final_esp.pdf.

${ }_{26}$ Véase Riquelme Cortado, R., España ante la Convención de Derecho del Mar, Murcia, Universidad de Murcia, 1990, pp. 73-74.

27 Hierrezuelo Conde, G., «La postura española en la Tercera Conferencia de las Naciones Unidas sobre el Derecho del Mar con respecto al Mar Territorial», Enciclopedia Virtual, eumed.net, p. 235 (http://www.eumed.net/librios-gratis/2015/1432/i9ndez.htm).

${ }_{28}$ Resolución AG 2070 (XX), de 16 de diciembre de 1965.

29 Resolución AG 68/523, de 11 de diciembre de 2013. 
retrocesión. La situación colonial de Gibraltar es, pues, incompatible con la Resolución 1514(XV) de 1960 y lo que es más preocupante, según se recoge sistemáticamente en las Resoluciones de la Asamblea General, incompatible con los Propósitos y Principios de la Carta de Naciones Unidas ${ }^{30}$.

Por tanto, el Reino Unido es sólo una Potencia Administradora de un territorio sometido a dominio colonial, que no dispone de un pueblo que tenga que ejercer su derecho de libre determinación y que tendría derecho a los recursos naturales en su beneficio. Por esta sencilla razón, no se le pueden atribuir más espacios, como serían los nuevos espacios marítimos aparecidos desde 1713, fecha del Tratado de Utrecht, e incluso, con posterioridad a las Resoluciones de Naciones Unidas sobre el debido proceso de descolonización por retrocesión e integridad territorial de Gibraltar a España.

\section{SITUACIÓN JURÍDICA DEL PUERTO DE GIBRALTAR Y SUS AGUAS INTERIORES}

Ante todo es importante señalar que no todas las fuentes procedentes del Derecho del Mar que vinculan a España y al Reino Unido tienen la misma procedencia. En este sector jurídico nos vamos a encontrar con normas estrictamente convencionales, que España y Reino Unido tienen expresamente aceptadas, vía adhesión o ratificación, como el Convenio de Ginebra sobre Mar Territorial y Zona Contigua ${ }^{31}$ y el de Alta $\mathrm{Mar}^{32}$, ambos de 1958, o con principios jurídicos bien reconocidos por la comunidad internacional como el principio de las libertades en alta mar, o normas de Derecho consuetudinario, como las que cristalizaron en la década de los setenta, hoy día vinculantes para España, referentes a la Zona Económica Exclusiva, por la doble vía consuetudinaria y convencional.

España y Reino Unido son partes en la Convención de $1982^{33}$ por lo que el origen de las fuentes jurídicas son claras y sus normas internas tienen que ser conformes e interpretadas en el marco de esta Convención.

En relación a los espacios marítimos adyacentes a Gibraltar, España sí reconoce la existencia de la administración británica sobre las aguas inte-

${ }^{30}$ La primera vez que la ONU señala esta cuestión en relación con Gibraltar fue en la Resolución 2353 (XII), de 19 de diciembre de 1967. Incluso la Resolución 2429 (XXIII), de 18 de diciembre de 1968, pide a la Potencia administradora que ponga término a la situación colonial de Gibraltar antes del 1 de octubre de 1969.

31 BOE núm. 307, de 24 de diciembre de 1971. Reino Unido entregó el instrumento de ratificación el 14 de marzo de 1960.

32 BOE núm. 309, de 27 de diciembre de 1971. Reino Unido entregó el instrumento de ratificación el 14 de marzo de 1960.

33 La Unión Europea recomendó a sus Miembros su ratificación, por lo que España, que la tenía firmada desde diciembre de 1984, la ratificó el 16 de enero de 1997, a pesar de las dificultades que para España ha supuesto el derecho de paso en tránsito por los estrechos internacionales y la creación de la Autoridad de los Fondos Marinos. BOE núm. 39, de 14 de febrero de 1997. Reino Unido entrega su instrumento de ratificación el 25 de julio de 1997. 
riores del puerto de Gibraltar, aun con sus ampliaciones, tal como ha hecho España en el Puerto de Algeciras y otros lugares ${ }^{34}$. En efecto, la existencia de un puerto en Gibraltar en 1713, cuando se produce el traspaso y que se hace constar en el Tratado de Utrecht lleva a la conclusión de que el Reino Unido, administrador actual de lo cedido en Utrecht, tiene competencias para administrar ese espacio marítimo de las aguas interiores de su puerto.

Aquí sí serían de aplicación las normas del Derecho del Mar relativas a este espacio (aguas interiores), por cierto no sólo las previstas en la Convención de Montego Bay, como ya he mencionado, y espacio no existente tampoco en 1713.

De acuerdo con el actual Derecho del Mar, cuya aplicación en relación con este espacio de aguas interiores del puerto de Gibraltar, ninguna de las Partes discute, las instalaciones portuarias se considerarán incluidas dentro de las aguas interiores, por tanto, la masa de agua que está comprendida entre la bocana del puerto o la instalación permanente más alejada de la costa, hasta la propia costa, dispone igualmente de una línea de base recta que permite considerar dicha masa de agua como aguas interiores. De hecho la Ley española actualmente vigente señala en su art. 8 que: «...Las aguas interiores

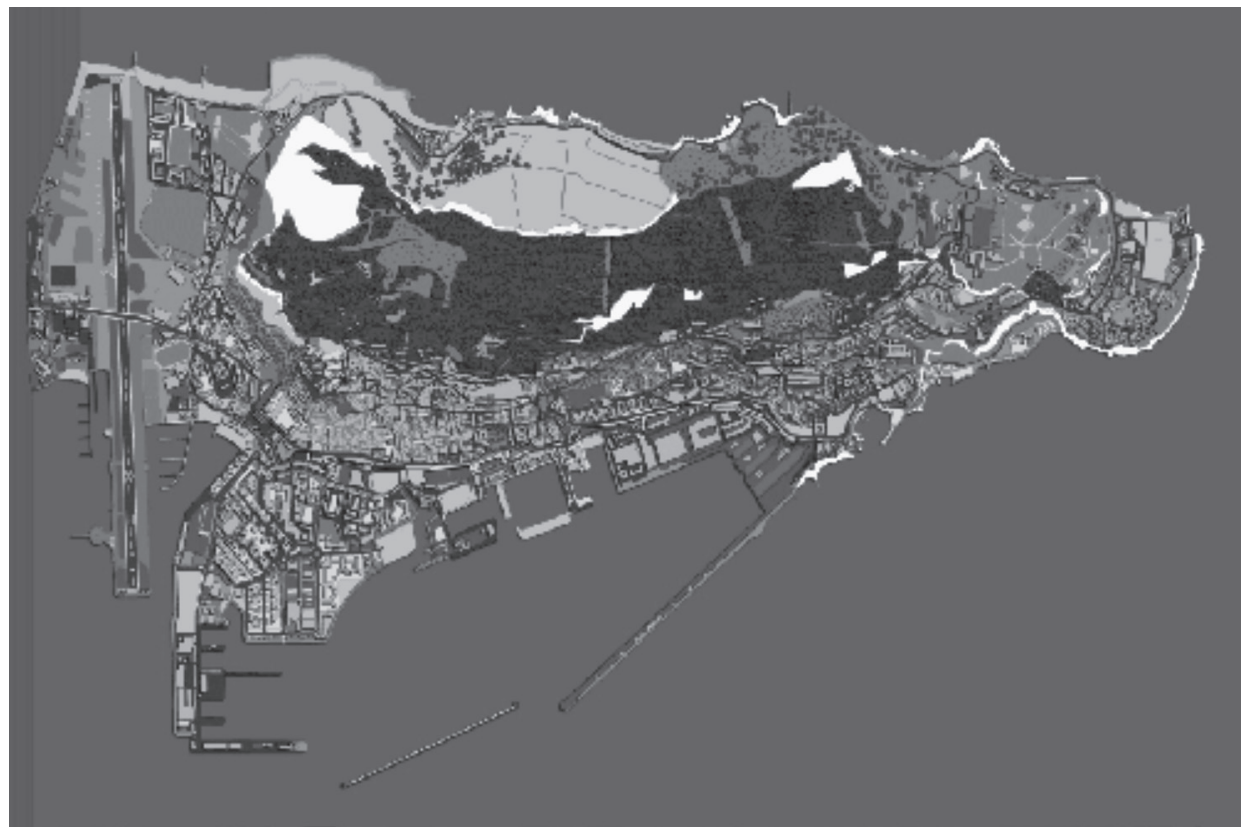

34 El Puerto de Algeciras se llama actualmente Puerto de la Bahía de Algeciras e incorpora al Puerto de La Línea y al Puerto de Tarifa, bajo la Autoridad Portuaria del Puerto de Algeciras. Para conocer sus dimensiones, extensiones, tráfico marítimo, servicios, etc., véase la última Memoria publicada de 2013 (http://www.apba.es/apba/MAnual2013/esp/memoria-anual13/HTML/index.html\#353/z). 
marítimas incluyen las de los puertos...» ${ }^{35}$. Por ello, como dice Tarik Atmane «el estatus jurídico de las aguas de la Bahía de Algeciras no está claro, aunque por lo menos hay que reconocer las aguas interiores del puerto de Algeciras $\mathrm{y}$, en su caso, las del Puerto de Gibraltar» ${ }^{36}$.

Esto implica derechos (aunque también obligaciones) ${ }^{37}$. Por ello, en efecto, España tiene que permitir la navegación hacia puerto o desde el puerto, desde o hasta mar abierto de aquellos buques que arriben o salgan desde el Puerto de Gibraltar.

La norma internacional es la libertad de acceso y de salida hacia o desde un puerto ${ }^{38}$, norma que fue elevada a la categoría de principio jurídico en la Sentencia Arbitral en el caso Arabia Saudí c. Arabian American Oil Company, de 23 de agosto de $1958^{39}$. Posteriormente este derecho de paso inocente ${ }^{40}$ a o desde un puerto fue considerado por la propia Corte Internacional de Justicia como una norma consuetudinaria internacional reflejada en el art. $18-1 .^{\circ}$ de la Convención de las Naciones Unidas sobre el Derecho del Mar ${ }^{41}$. En realidad este paso inocente a o desde los puertos refleja la superposición de reglas de Derecho internacional que refleja la libertad de acceso a los puertos ${ }^{42}$. Hay, incluso quien habla de un derecho independiente del derecho de paso inocente por el mar territorial de un Estado ${ }^{43}$.

España, en su Ley 10/1977, de 4 de enero, sobre mar territorial (BOE de 8 de enero de 1977), fijó la extensión general de sus aguas territoriales en 12 millas, que se contarán a partir de las líneas de base rectas que haya establecido el Gobierno ${ }^{44}$ o, en caso contrario, por la línea de bajamar escorada.

Por tanto, para el ejercicio de este derecho, aplicable únicamente a los buques mercantes que necesiten atravesar el mar territorial español para

35 Real Decreto Legislativo 2/2011, de 5 de septiembre, por el que se aprueba el Texto Refundido de la Ley de Puertos del Estado y de la Marina Mercante, BOE núm. 253, de 20 de octubre de 2011.

${ }^{36}$ Atmane, T., España y Marruecos frente al Derecho del Mar, La Coruña, NetBiblo, 2007, p. 8.

37 Véase en este sentido, Marten, B., Port State Jurisdiction and the Regulation of International Merchant Shipping, Heidelberg y otros, Springer International Publishing, 2014.

38 Convenio de Ginebra sobre el Régimen Internacional de los Puertos Marítimos, de 9 de diciembre de 1923. Tanto Reino Unido como España son signatarios de este Convenio.

39 En este sentido, el Tribunal señala expresamente que un "grand principe de droit international public exige que les ports de mer de chaque Etat soient ouverts aux navires de commerce étrangers, et que leur fermeture n'est admissible que si les intérêts vitaux de l'Etat l'exigent». Véase al respecto, los comentarios de BASTID, S., "Le Droit International Public dans la Sentence Arbitrale de'ARAMCO», Annuaire Française de Droit International, vol. VII, 1961, pp. 300-311, especialmente p. 306 (http://www.persee.fr/ web/revues/home/prescript/article/afdi_0066-3085_1961_num_7_1_1091).

40 Véase HakapäÄ, K., "Innocent passage», The Max Planck Encyclopedia of Public International Law, Oxford, Oxford University Press, vol. IV, 2012, pp. 209-219.

41 Caso Nicaragua c. Estados Unidos, ICJ, Reports núm. 13, 1986, párr. 214.

42 O'Connell, D. P. y Shearer, I., The International Law of the Sea, vol. I, Oxford, Clarendon Press, 1984, p. 269.

${ }^{43}$ YANG, H., Jurisdiction of the Coastal State over Foreign Maerchant Ships in Internal Waters and the Territorial Sea, Berlín-Heidelberg, Springer, 2006, p. 151.

${ }_{44}$ Vuelvo a recordar que España tiene establecidas estas líneas de base rectas en los Decretos 627/1976, de 5 de marzo (BOE de 30 de marzo de 1976), modificado por el Decreto 2510/1977, de 5 de agosto (BOE de 7 de septiembre de 1977), actualmente en vigor. 
arribar al puerto de Gibraltar, ejerciendo su derecho de paso inocente, de acuerdo con el art. 25-2 de la Convención de Naciones Unidas sobre el Derecho del Mar, el Estado ribereño (en este caso, España) no podría exigir más que medidas protectoras para su navegación, especialmente en materia medioambiental ${ }^{45}$. En este sentido, se podría perder la inocencia del paso en caso de incumplimiento de este tipo de normas ${ }^{46}$.

El Derecho internacional del Mar permite que el Estado ribereño dicte leyes y reglamentos relativos al paso inocente por el mar territorial, en concreto, para la prevención de las infracciones de sus leyes y reglamentos aduaneros, fiscales, de inmigración y sanitarios.

Es más, el Texto Refundido de la Ley de Puertos del Estado y de la Marina Mercante (BOE de 20 de octubre de 2011), en su art. 301, prevé «a efectos de prevenir la realización de actividades ilícitas o el ejercicio de cualquier tráfico prohibido, el Gobierno podrá impedir, restringir o condicionar la navegación de determinada categoría de buques civiles» por su mar territorial.

Pero si esto es en relación con los buques mercantes, el régimen jurídico para los buques de guerra es diferente.

Como regla general, en el Derecho internacional clásico, un Estado no podía prohibir el paso de buques de guerra en su mar territorial y no requería obligatoriamente autorización o notificación previa. Lo que tenía el Estado era el derecho de regular las condiciones de dicho paso, debiendo los submarinos navegar emergidos ${ }^{47}$. El art. 30 de la Convención de Naciones Unidas sobre el Derecho del Mar de 1982, establece que:

"Cuando un buque de guerra no cumpla las leyes y reglamentos del Estado ribereño relativos al paso por el mar territorial y no acate la invitación que se le haga para que los cumpla, el Estado ribereño podrá exigirle que salga inmediatamente del mar territorial» ${ }^{48}$.

De esta forma, como puede comprobarse, esto daría lugar a una variedad enorme de práctica estatal ${ }^{49}$, pero, en todo caso, las normas del Estado cos-

45 No es fácil determinar las responsabilidades medioambientales del Estado del puerto, sobre todo cuando están atravesando un mar territorial para llegar a un puerto con aguas interiores de otro Estado. Véase ANDERson, D., Port States and Environmental Protection, La Haya, Martinus Nijhoff Publishers, 1999, p. 342. Igualmente Johnson, L. S., Coastal State Regulation of International Shipping, Oxford, Oxford University Press, 2004, pp. 35 y 46.

46 Espaliú Berdud, C., “¿Un derecho de paso "inocente” por el mar territorial de los buques extranjeros que transportan sustancias altamente contaminantes?», Revista Española de Derecho Internacional, vol. 60, 2008, pp. 147-162. Véase también Bou FrANCH, V., «Freedom of navigation versus pollution by oil from vessels: the point of view of coastal States», en CASADO RAIGÓN, R. (ed.), L'Europe et la mer, pêche, navigation et environnement marin, Bruselas, Bruylant, Université de Bruxelles, 2005, pp. 253-288.

47 La evolución de estas reglas puede verse en TANAKA, Y., The International Law of the Sea, Cambridge, Cambridge University Press, 2012, pp. 88 y ss.

48 EsPaliú BERDUD, C., «La nature juridique du passage inoffensif des navires de guerre étrangers dans la mer territoriale: régime contenu dans la Convention des Nations Unies sur le droit de la mer et régime existant en marge de la Convention», en CASADO RAIGÓN, R. (ed.), L'Europe et la mer, pêche, navigation et environnement marin, Bruselas, Bruylant, Université de Bruxelles, 2005, pp. 379-392.

${ }^{49}$ Agyebeng, W. K., "Theory in Search of Practice: The right of Innocent Passage in the Territorial Sea», Cornell International Law Journal, 2006, núm. 39, pp. 396-398. 
tero no podrían evitar el derecho de paso inocente de los buques de guerra ${ }^{50}$, más que en la medida en que supongan un peligro para la seguridad, el medio ambiente o la navegación ${ }^{51}$.

El art. 51 de la reciente Ley Española de Navegación Marítima, de 201452, sólo hace mención a la navegación de estos buques por aguas interiores. Nada dice sobre el mar territorial.

Muchos Estados exigen a determinados tipos de buques autorización previa, notificación previa, prohibición e incluso hay tratados internacionales que requieren formalidades específicas ${ }^{53}$.

España tiene regulado el paso de buques de guerra por mar territorial español en normas específicas: la Orden 25/1985, de 23 de abril, del Ministerio de Defensa de 23 de abril de 1985 por la que se aprueban las normas para las escalas de los buques de guerra extranjeros en puertos o fondeaderos españoles y su paso por el mar territorial español en tiempos de paz ${ }^{54}$. Su art. 11 es claro: «No se requiere autorización especial para el paso de buques de guerra extranjeros por el mar territorial español, en el que están obligados a respetar "el paso inocente", con arreglo a las normas consuetudinarias del Derecho internacional». Por tanto, no habría que solicitar permiso, ni se requiere notificación previa.

Cuestión diferente es el acceso a los puertos españoles de los buques de guerra extranjeros que tiene una regulación diferente, pero es una cuestión que no nos interesa en este análisis.

Otra cosa sería también el acceso de buques de guerra con carga nuclear o cualquier otro armamento, que deberían regirse, en el caso de buques de guerra británicos u otros de Estados de la OTAN, por los acuerdos normali-

50 La práctica de los Estados es muy variada en cuanto a las exigencias de autorización, de notificación, de limitación del número de buques de guerra que pueden simultáneamente utilizar el derecho de paso inocente, de no exigir pero reservarse el derecho de hacerlo, etc. Véase EsPaLIú BERDUD, C., Le passage inoffensif des navires de guerres étranger dans la mer territoriale: portée du régime contenu dans la Convention des Nations Unies, Bruselas, Bruylant, 2006, nota 1.

51 Para conocer los debates sobre el derecho de paso inocente de los buques de guerra durante la III Conferencia sobre el Derecho del Mar, véase OxMAN, B. H., «Le régime des navires de guerre dans le cadre de la Convention des Nations Unies sur le Droit de la mer», Annuaire Français de Droit International, 1982, pp. 811-850. Más recientemente, véase también ESPALIÚ BERDUD, C. y CASADO RAIGóN, R., «El paso inocente de los buques de guerra extranjeros por mar territorial; alcance del régimen de la CNUDM», Revista Española de Derecho Internacional, vol. 57, 2005, pp. 777-800.

52 Ley 14/2014, de 24 de julio, de Navegación Marítima, BOE núm. 180, de 25 de julio de 2014.

53 Alonso Martínez, G., El Derecho de Paso Inocente de los Buques de Guerra a través del Mar Territorial, TFM del Máster en Derecho Internacional Público, Universidad Complutense de Madrid, 2013, p. 30 (http://eprints.ucm.es/22297/1/TFM-Gustavo_Alonso_Mart\%C3\%ADnez.pdf).

${ }^{54}$ Orden 25/1985, de 23 de abril, del Ministerio de Defensa, por la que se aprueban las normas para las escalas de los buques de guerra extranjeros en puertos o fondeaderos españoles y su paso por el mar territorial español en tiempos de paz, BOE núm. 115, de 14 de mayo de 1985. Un estudio de esta norma puede verse en DíEz-HochlEITNER, J., «Régimen de navegación de los buques de guerra extranjeros por el mar territorial español y de sus escalas en puertos españoles», Revista Española de Derecho Internacional, vol. 38, 1986, pp. 543-569. 
zados de la OTAN, donde no se solicita información ${ }^{55}$. Sin embargo, España presentó una reserva en este Acuerdo por la que indicaba:

«b) No permitir la escala en puertos españoles a buques que procedan directamente de Gibraltar

c) No permitir la escala en puertos españoles a los buques que a continuación de su escala en puerto español se dirijan directamente a Gibraltar» ${ }^{56}$.

Como puede observarse no impide directamente las escalas portuarias en Gibraltar sino que castiga a los que las hagan. Es una manera de reafirmar su posición jurídico-política en la materia.

España no ha establecido aguas interiores en la Bahía de Algeciras, más allá de las legalmente correspondientes al Puerto de la Bahía de Algeciras ${ }^{57}$. Ello es así porque el Derecho internacional no le permite establecer un punto de apoyo en Punta Europa (Gibraltar) que sería necesario para cerrar la embocadura de la Bahía como aguas interiores, desde Punta Carnero. Por tanto, a los efectos jurídicos, las aguas de la Bahía que no correspondan con las aguas portuarias, son mar territorial. Y, en el mar territorial, el régimen de la navegación es el que he señalado tanto para los buques mercantes como para los buques de guerra.

La existencia de la controversia de Gibraltar impide a España, también, designar el resto de las aguas de la Bahía de Algeciras (diferentes de las aguas del Puerto) como aguas interiores, aunque nada impediría que lo pudiera hacer, si estuviera de acuerdo en hacerlo por la mediana que exige el Reino Unido, cosa que no quiere (ni debe) hacer España, para no reconocer la gestión de la proyección de las aguas marítimas de Gibraltar, por parte del Reino Unido $^{58}$. Es verdad que el límite máximo establecido en la Convención de 1982 para establecer el mar territorial es de 12 millas $^{59}$, aunque éste no tiene por qué ser fijado en dicha distancia.

Un problema que sí genera enormes controversias es el acceso al puerto de Gibraltar de buques de guerra provistos de armas nucleares o de propulsión nuclear, no tanto por su dimensión de seguridad militar como de seguridad medioambiental.

55 OTAN STANAG 1100, Procedimientos para las visitas de buques de la OTAN a puertos de naciones OTAN y NO-OTAN (Procedure for Visits to NATO and NON-NATO armed forces by Naval Ships of NATO Nations), implantado en España desde el 1 de julio de 1997.

56 Gómez de Olea Bustinza, P., «Aspectos Internacionales y Proyectos Existentes», Consideraciones sobre los Estatutos de las Fuerzas Armadas en actividades internacionales, Cuadernos de Estrategia, Ministerio de Defensa, 1998, núm. 94, p. 60 (dialnet.unirioja.es/descarga/articulo/2782851.pdf).

57 El Puerto de la Bahía de Algeciras alcanza no sólo el Puerto de Algeciras, sino también el de La Línea, las instalaciones portuarias de los puertos industriales de Acerinox, Refinería, Pantalán CHS, Endesa Puerto, etc., así como las del Puerto de Tarifa. Véase http://webserver.apba.es/portal/page?_pageid=388,171476\&_dad=portal\&_schema $=$ PORTAL.

58 El Reino Unido ha establecido un franja de tres millas en la parte oriental del Peñón y hasta la mediana de la Bahía de Algeciras, como mar territorial a las que llama aguas gibraltareñas o aguas del Almirantazgo Británico.

59 El art. 3 de la Convención establece lo siguiente: «Todo Estado tiene derecho a establecer la anchura de su mar territorial hasta un límite que no exceda de 12 millas medidas a partir de las líneas de base determinadas de conformidad con esta Convención». 
Ha habido varios casos donde los Estados ribereños han denegado el derecho de paso inocente por el riesgo de contaminación que suponía la presencia de buques de guerra armados o propulsados con energía nuclear, máxime si estaban averiados. Por ejemplo, en el caso de un buque soviético en mar territorial japonés, en 1980, otro, en 1985, de buques chinos en mar territorial surcoreano o de submarinos norteamericanos en Grecia en $1987^{60}$.

\section{LA APLICACIÓN DEL PRINCIPIO LEX SPECIALIS DEROGAT LEGI GENERALI}

Además de la aplicación clara de las Resoluciones de Naciones Unidas sobre la descolonización de Gibraltar que impiden extender los espacios de dominación colonial, ¿sería posible, acorde con el Derecho internacional general, limitar los derechos para el ejercicio de la soberanía o la jurisdicción en los espacios marítimos?

Si aplicamos el principio jurídico lex specialis derogat legi generali ${ }^{61}$ se podría afirmar que una norma convencional previa e incluso posterior a la Convención de Naciones Unidas sobre el Derecho del Mar podría modificar los efectos jurídicos de este texto convencional. Ello es así porque «entre los tratados que son iguales [...] se debe dar preferencia a aquel que es más específico y con enfoques más próximos al objeto que se tiene por delante. Las disposiciones especiales son normalmente más eficaces que las generales» ${ }^{62}$.

En efecto, «una regla en particular puede ser considerada como una aplicación de la regla general en una circunstancia dada. Es decir, puede dar instrucciones sobre lo que una regla general requiere en el caso que nos ocupa. Por otra parte, una regla en particular puede ser concebida como una excepción a la regla general. En este caso, la excepción particular deroga la norma general. La máxima lex specialis derogat legi generalis es tratada como una norma de conflicto» ${ }^{63}$.

En materia del Derecho del Mar, la norma general es la Convención de las Naciones Unidas sobre el Derecho del Mar, bien en su dimensión conven-

60 Todos ellos citados por Gómez de Olea Bustinza, P., op. cit., nota 56, pp. 72-73.

61 Junto a los principios jurídicos lex superior derogat legi inferiori y lex posterior derogat legi priori, forman criterios para la solución de antinomias jurídicas. Véase PRIETO SANCHís, L., «Observaciones sobre las antinomias y el criterio de ponderación», en Cuadernos de Derecho Público, 2000, núm. 11, p. 10 .

62 Texto original: "Among agreements which are equal [...] that should be given preference which is most specific and approaches most nearly to the subject in hand, for special provisions are ordinarily more effective than those that are general», en Grotius, H., De Jure Belli Ac Pacis, bk II, sect. XXIX.

${ }_{63}$ Texto original: "A particular rule may be considered an application of the general rule in a given circumstance. That is to say, it may give instructions on what a general rule requires in the case at hand. Alternatively, a particular rule may be conceived as an exception to the general rule. In this case, the particular derogates from the general rule. The maxim lex specialis derogate lex generalis is usually dealt with as a conflict rule. However, it need not be limited to conflict», en KosKENNIEMI, M., Study on the Function and Scope of the Lex Specialis Rule and the Question of 'Self Contained Regimes, UN Doc. ILC(LVI)/SG/ FIL/CRD.1 and Add.1 (2004), at 4. 
cional, bien en su proyección consuetudinaria. Ahora bien, hay que tener en cuenta todos los elementos sistémicos.

La Sentencia de la Corte Internacional de Justicia de 20 de febrero de 1969 en relación con la Plataforma Continental del Mar del Norte deja claro un aspecto que me interesa destacar en relación con la Bahía de Algeciras. El método de la equidistancia (que reivindica Reino Unido en la Bahía de Algeciras) no es obligatorio para las partes, la delimitación debe hacerse teniendo en cuenta todas las circunstancias pertinentes y los principios o métodos aplicables a los límites adyacentes marítimos son distintos según los casos ${ }^{64}$. Al respecto, el Prof. Héctor Cuadra Moreno considera «a propósito de una pretendida regla de equidistancia en la delimitación de la plataforma continental, el juez toma en consideración las proclamaciones de los gobiernos y los trabajos de las comisiones (especialmente de la Comisión de Derecho Internacional de la ONU) y concluye que, lejos de derivar de un principio inherente, es la racionalización a posteriori de soluciones juzgadas oportunas» ${ }^{65}$.

La norma especial lo sería el propio Tratado de Utrecht, que uno de sus firmantes, España, interpreta en el sentido que el Derecho internacional permite a los Estados limitar derechos o competencias, de acuerdo con las normas de interpretación recogidas en el art. 31 de la Convención de Viena sobre el Derecho de los Tratados de 1969. Por tanto, se puede interpretar que el texto del art. X del Tratado de Utrecht deja clara la voluntad de las partes:

«Para evitar cualesquiera abusos y fraudes en la introducción de las mercaderías, quiere el Rey Católico, y supone que así se ha de entender, que la dicha propiedad se ceda a la Gran Bretaña sin jurisdicción alguna territorial y sin comunicación alguna abierta con el país circunvecino por parte de tierra. Y como la comunicación por mar con la costa de España no puede estar abierta y segura en todos los tiempos, y de aquí puede resultar que los soldados de la guarnición de Gibraltar y los vecinos de aquella ciudad se vean reducidos a grandes angustias, siendo la mente del Rey Católico sólo impedir, como queda dicho más arriba, la introducción fraudulenta de mercaderías por la vía de tierra, se ha acordado que en estos casos se pueda comprar a dinero de contado en tierra de España circunvecina la provisión y demás cosas necesarias para el uso de las tropas del presidio, de los vecinos y de las naves surtas en el puerto.

Pero si se aprehendieran algunas mercaderías introducidas por Gibraltar, ya para permuta de víveres o ya para otro fin, se adjudicarían al fisco, y presentada queja de esta contravención del presente Tratado serán castigados severamente los culpados» ${ }^{66}$.

La expresión «sin jurisdicción alguna territorial» ${ }^{67}$ es en la que se funda España para impedir la proyección de espacios marítimos que sean administrados por la Potencia Administradora de Gibraltar.

${ }^{64}$ CIJ, Rec., 1969.

65 Cuadra Moreno, H., «La contribución de la jurisprudencia de la Corte Internacional al Derecho Internacional», Revista Mexicana de Derecho Comparado, vol. 15, 1972, pp. 443-444.

66 Art. X del Tratado de Utrecht de 13 de julio de 1713.

${ }^{67}$ En los otros dos textos auténticos de la redacción del Tratado se indica: en latín: «sine iurisdictione quapiam territoriali»; en inglés: «without any territorial jurisdiction». 
Pero, además, el mismo art. X está señalando el límite a las aguas interiores del puerto, sin mayor jurisdicción marítima con las siguientes palabras que pueden leerse en el mismo, cuando se exige que no «se dé entrada ni acogida a las naves de guerra moras en el puerto de aquella Ciudad, con lo que se puede cortar la comunicación de España a Ceuta, o ser infestadas las costas españolas por el corso de los moros. Y como hay tratados de amistad, libertad y frecuencia de comercio entre los ingleses y algunas regiones de la costa de África, ha de entenderse siempre que no se puede negar la entrada en el puerto de Gibraltar a los moros y sus naves que sólo vienen a comerciar».

Es decir, el Tratado de Utrecht mismo está señalando no sólo la expresión «sin jurisdicción alguna», sino que únicamente reconoce el ius communicationis marítimo de forma muy limitada a la entrada y salida del Puerto de Gibraltar para naves comerciales, no para naves de guerra y con el único objetivo de comerciar. Es decir, entrada y salida del Puerto.

Tal como reconoció la Corte Internacional de Justicia en su Opinión Consultiva sobre la Competencia de la Asamblea General para la Admisión de un Estado en las Naciones Unidas, siguiendo las reglas de interpretación del Derecho de los Tratados,

«La primera obligación de un tribunal al que incumba interpretar y aplicar las disposiciones de un tratado es tratar de darles efecto conforme a su sentido natural y corriente en el contexto en que aparecen. Si las palabras pertinentes, cuando se les atribuye su significado natural y corriente tienen sentido en su contexto no hay que investigar más. Por el contrario, si las palabras, cuando se les atribuye su significación natural y ordinario, son equívocas o conducen a resultados irracionales, es entonces - solamente entonces- cuando la Corte debe buscar, a través de otros métodos, lo que en realidad tenían en mente» ${ }^{68}$.

Es más, si tenemos en cuenta el contexto sistémico del Tratado en el sentido de que la interpretación del texto es compatible con las obligaciones asumidas ${ }^{69}$, donde España acepta forzadamente la cesión de Gibraltar, como imposición, su voluntad de no otorgar más espacios que los que menciona expresamente, es evidente. A esto se le llama ocassio legis, es decir, «aquella situación concreta que fue la causa eficiente de la aprobación del tratado» ${ }^{70}$.

De cualquier manera, estando claro el texto «sin jurisdicción alguna», que no admite interpretación, más allá del sentido de sus propias palabras, no cabría otro tipo de interpretación, puesto que la textual es la que tiene primacía ${ }^{71}$. Otra cosa diferente sería qué habría que interpretar por «jurisdicción», pero, sea cual sea el contenido que queramos darle a esta expresión

\footnotetext{
68 Caso Ambatielos, 1952, p. 8. Esta idea fue reforzada por la propia Corte Internacional de Justicia en sus sentencias del Asunto del Templo de Préah Vihéar, Excepciones Preliminares, 1961, p. 32 y del Asunto de las plataformas petrolíferas. Excepción Preliminar, 1996, p. 818.

${ }^{69}$ McLachlan, C., "The principle of systemic interpretation and article 31 (3c) of the Vienna Convention», International and Comparative Law Quarterly, 2005, núm. 54, p. 290.

70 Novak Talavera, F., «Los Criterios para la Interpretación de los Tratados», Themis, Revista de Derecho, 2013, núm. 63, p. 84.

71 Villiger, M., Commentary on the 1969 Vienna Convention on the Law of Treaties, Leyden, Martinus Nijhoff, 2009, p. 436.
} 
jurídica, podemos acudir a la propia Corte Internacional de Justicia cuando, en el Asunto de la Plataforma Continental del Mar Egeo, precisa que «es difícilmente concebible que se intentara dar a expresiones como "jurisdicción doméstica" y "estatuto territorial" un contenido invariable cualquiera fuera la evolución subsiguiente del Derecho internacional» ${ }^{72}$.

Por tanto, «sin jurisdicción alguna» puede suponer claramente una exclusión de cualesquiera derechos y competencias fuera de los espacios cedidos. Esto es así por las ya mencionadas reglas de interpretación de un Tratado Internacional y por la existencia de un principio aplicable a dicha interpretación que es de sentido común, Ubi Lex Distinguit, Nec Nostrum Est Distinguere (donde no distingue el legislador, no debe distinguir el intérprete) ${ }^{73}$.

Nadie puede interpretar que con los términos «sin jurisdicción alguna» se refiere exclusivamente a los espacios terrestres porque no se diferencia. Es verdad que no había espacios marítimos en 1713, tal como los conocemos hoy pero la voluntad de los negociadores españoles era clara: no dar más de lo que se entregaba en Utrecht y ello por cesión forzosa. Por tanto, intentar hacer una interpretación contraria al principio jurídico señalado y a las reglas de interpretación es, cuando menos, inconsistente ${ }^{74}$.

Claro que los Tratados de la época no incorporaban los espacios marítimos pero ni siquiera en el propio Tratado de Utrecht, en la cesión de Menorca, señala los mismos límites que a Gibraltar, ni señala las preocupaciones de España en relación con el contrabando y con la seguridad marítima. Por tanto, «sin jurisdicción alguna» expresa la voluntad jurídica de ceder lo mínimo posible, aquello que era imprescindible a los objetivos del Tratado de Utrecht. Por ello, no comparto el análisis, en mi opinión poco fundado en Derecho, basándose en documentos o doctrinas que nada aportan a la aplicación del Derecho. El Prof. Verdú nos recuerda la existencia de «un principio bien asentado por el Derecho internacional y reconocido por el Tribunal (sic) Internacional de Justicia que los derechos soberanos de los Estados deben ponderarse y modularse de acuerdo con los principios y criterios existentes en el Derecho internacional, no aceptándose declaraciones unilaterales si no son conformes con las reglas y principios del Derecho internacional... ${ }^{75}$. Exacto, salvo que las declaraciones unilaterales constituyan normas de Derecho, como pueden ser aquellas declaraciones interpretativas de los tratados, aceptadas por las Partes o por los tribunales de justicia ${ }^{76}$ o declaraciones unilaterales capaces de crear obligaciones jurídicas ${ }^{77}$.

72 Asunto de la Plataforma Continental del Mar Egeo, Reports, 1978, p. 32.

73 Bustamante Bustamante, N., Locuciones Latinas en Materia Jurídica, Bloomington, Palibrio, 2012, p. 413.

${ }_{74}$ No comparto el análisis del Prof. Verdú en este sentido. Véase Verdú BAEZA, J., La controversia sobre las aguas de Gibraltar..., op. cit., nota 5.

75 Ibid., p. 109.

76 Riquelme CoRtado, R., Reservas a los tratados: lagunas y ambigüedades del Régimen de Viena Lagunas y ambigüedades del Régimen de Viena, Murcia, Universidad de Murcia, 2004, pp. 33 y ss.

77 Véanse los Principios Rectores aplicables a las Declaraciones Unilaterales de los Estados capaces de crear Obligaciones Jurídicas, Texto aprobado por la CDI en su 58. ${ }^{\circ}$ periodo de sesiones, en 2006. Véase Doc. A/61/10 de la Asamblea General. 
Esta misma interpretación es la que permite que el Tratado de París de 9 de febrero de 1920, al que España se adhirió el 2 de noviembre de $1925^{78}$, permita que, aun reconociendo la soberanía noruega sobre el archipiélago Svalbard o Spitzberg, se limite el derecho soberano de jurisdicción en lo que la Convención de Naciones Unidas sobre el Derecho del Mar llamaría cincuenta años más tarde la Zona Económica Exclusiva o Plataforma Continental para que las Partes Contratantes, entre ellas España, ejercieran en igualdad de condiciones la posibilidad de extracción de recursos naturales, incluyendo la pesca y la minería aunque Noruega pueda imponer medidas de conservación ${ }^{79}$. De hecho, hoy día se considera esa ZEE como fundamental para la flota bacaladera española.

Noruega ha intentado, en alguna ocasión, argumentar la existencia del nuevo Derecho del Mar pero la realidad es que el Tratado está vigente e incluso se van adhiriendo al mismo más Estados ${ }^{80}$.

Por tanto, la existencia de una norma convencional previa o posterior podría limitar la soberanía, la jurisdicción y el ejercicio de competencias o cualquier derecho propio reconocido en una norma de carácter general.

De esta forma, si interpretamos que, de acuerdo con el tenor literal del Tratado de Utrecht, España no transfiere competencias en ningún espacio fuera de los cedidos, incluyendo, por tanto, los espacios marítimos, además de la existencia de normas imperativas, como ya he dicho antes, puede exigir la aplicación de normas especiales frente a la posible aplicación de las normas generales.

Esto no quiere decir que Gibraltar carezca de proyección marítima sino que esas aguas son de soberanía española, por no haber sido transferidas ni cedidas por el Tratado de Utrecht y estar incursas en el derecho de integración territorial del proceso descolonizador que preconiza Naciones Unidas para el territorio de Gibraltar, por lo que no puede deducirse derecho alguno para que sean administradas por el Reino Unido.

Otra cosa es, como ya he dicho anteriormente, que las consecuencias del ejercicio de derechos pueda resultar incompatible con otras normas del Derecho internacional, como las que regulan la obligación del arreglo pacífico de controversias, por lo que España está obligada a utilizar medios pacíficos, lo que le impide el uso de la fuerza. Pero esto en ningún momento supone dejación del Derecho, sino, al contrario, legitimidad con el mismo.

En relación con la aplicación del Tratado de Utrecht, que ya hemos dicho que ambas Partes aceptan como vigente para justificar la presencia adminis-

78 Gaceta de Madrid, 13 de abril de 1929.

79 De hecho, Noruega estableció una Zona de Protección Pesquera a través del Decreto de 3 de junio de 1977. Véase http://www.magrama.gob.es/es/pesca/temas/planes-de-gestion-y-recuperacion-deespecies/tratadoparis.aspx.

${ }^{80}$ Corea, por ejemplo, lo hizo el 7 de septiembre de 2012 (BOE núm. 31, de 5 de febrero de 2013); Países Bajos hizo una extensión territorial de aplicación del Tratado el 10 de octubre de 2010 (BOE núm. 105, de 2 de mayo de 2012). 
tradora del Reino Unido en el territorio, hay una curiosa, por interesante, teoría que formula el Prof. Alejandro del Valle y a la que quizás no se le ha prestado suficiente atención.

El Prof. del Valle parte del principio de que en Utrecht se cede la ciudad (junto al puerto y fortaleza) pero no la montaña calpense. De esta forma el Prof. del Valle sugiere lo siguiente:

«En realidad una hipótesis admisible es que durante las negociaciones de Utrecht se acordara la cesión sólo del territorio intramuros de la Plaza: la Ciudad más el Castillo (con los complementarios puerto, defensas y fortaleza), pero ningún territorio fuera de las murallas. A diferencia del art. XI referido a Menorca - que habla de la isla y de lugares en la isla- en el art. X no hay referencias a cesión de elementos naturales o de defensa natural de la península gibraltareña, sino a edificaciones humanas. Si esto es así, entonces supondría que en el Tratado de Utrecht no se cedió la montaña completa, en particular la parte de levante o cara este de la montaña, donde, sencillamente, no había fortificación ni población alguna» ${ }^{81}$.

Las consecuencias de esta reinterpretación estarían relacionadas con el tema de las aguas adyacentes, ya que se podría reformular la doctrina de la costa seca «apoyándose en la no cesión de la montaña completa, ni de la cara este del Peñón, por lo que en realidad la base jurídica del no reconocimiento de aguas a Gibraltar no sería estrictamente la costa seca, sino la españolidad de la tierra que es proyectada en sus aguas hacia el este de la montaña» ${ }^{82}$.

El mismo autor reconoce la dificultad de esta nueva reinterpretación del Tratado de Utrecht porque aquí sí que podría oponerse la doctrina de la prescripción adquisitiva ${ }^{83}$.

\section{LA DOCTRINA DE LA «COSTA SECA»}

Es verdad que existe un principio en Derecho internacional que señala que «el territorio domina el mar» para determinar que todo espacio territorial costero es, por principio, el que proyecta sus competencias sobre el $\operatorname{mar}^{84}$.

Ahora bien, en efecto es un principio, que podría ser rebatido por una norma de carácter imperativo, por otro principio, por una norma convencio-

\footnotetext{
81 Del Valle Gálvez, A., «España y la Cuestión de Gibraltar a los 300 años del Tratado de Utrecht», ARI, Real Instituto Elcano, 2013, núm. 23, p. 9.

82 Ibid., p. 12.

83 En relación con la prescripción adquisitiva en Derecho internacional, véase BRUNO BoLOGNA, A., «Los derechos de Inglaterra sobre las islas Malvinas: prescripción», Revista de Estudios Internacionales, vol. IV, 1983, núm. 4, pp. 775-783.

${ }^{84}$ Este principio ha sido confirmado por la Corte Internacional de Justicia en el «Asunto Relativo a la Delimitación de la Plataforma Continental del Mar del Norte (Reports, 1969, p. 51, párr. 96); «Asunto Relativo a la Delimitación de la Plataforma Continental del Mar Egeo» (Reports, 1978, p. 36, párr. 86); Asunto Relativo a la Delimitación Marítima entre Qatar y Berhein (Reports, 2011, p. 97, párr. 185-8); Asunto Relativo a la Diferencia Territorial y Marina entre Nicaragua y Honduras en el Mar del Caribe (Reports, 2007, párrs. 113-114).
} 
nal o, incluso, por la práctica internacional. En esta colisión de normas, la imperativa sería preferente y habría que estudiar la norma mejor aplicable, en el caso de colisión con normas convencionales o generales.

España argumenta, como hemos visto, que los espacios marítimos adyacentes a Gibraltar no fueron cedidos en el Tratado de Utrecht, a excepción de las aguas interiores de su puerto. De hecho, hay documentación probada de que se permitiría a los habitantes de Gibraltar venir por mar a España, a comprar mercaderías ${ }^{85}$. Por tanto, se les estaba haciendo una concesión personal que no territorial.

En este sentido, la Nota Verbal 1515/11, de 12 de julio de 2007, señala la titularidad de las aguas adyacentes al Peñón como espacios marinos de soberanía española. Textualmente dice «...cabe recordar que España no reconoce la soberanía o jurisdicción británica sobre otros espacios que los expresamente cedidos en el Artículo X del Tratado de Utrecht. Es decir, "la ciudad y castillo de Gibraltar, juntamente con su puerto, defensa y fortaleza que le pertenecen". Por tanto, el Peñón no genera espacios marinos y los espacios adyacentes a la costa gibraltareña son espacios sometidos a la soberanía y jurisdicción de España» ${ }^{86}$.

Si oponemos la doctrina de la costa seca ${ }^{87}$ llamada también costa estéril, al principio del «territorio domina el mar», la delimitación marítima española debe establecerse a los efectos del ejercicio de su soberanía, en la orilla de la bajamar más pronunciada. Por tanto, Gibraltar, como territorio no autónomo, administrado por el Reino Unido de acuerdo con el territorio cedido en Utrecht, no puede proyectar sus competencias en estos espacios marítimos.

Nweihed Kaldone considera que "La "costa seca", la costa que no engendra mar territorial, puede darse, pero a título excepcional y en forma convencional» ${ }^{88}$. Por tanto, no la niega aunque sólo la afirma a título excepcional y en forma convencional.

\section{María Querol, por su parte señala que}

«el caso del San Juan pone en evidencia que el sistema de delimitación de la costa seca no se condice con el contenido de este derecho al uso equitativo y razonable. Mal puede un Estado determinado utilizar las aguas de un sistema hídrico del que es parte naturalmente, si no tiene acceso a sus aguas en virtud de una disposición convencional. Esta dicotomía entre la regla consuetudinaria del

85 Ballesteros, Á., Los contenciosos de la política exterior de España, Ceuta, Instituto de Estudios Ceuties, 2005, p. 30 .

86 Ministerio de Asuntos Exteriores y de CoOperación, La Cuestión de Gibraltar..., op. cit., nota 10, p. 14. Esta idea fue reiterada en la Respuesta Parlamentaria del Gobierno Español núm. 39.640 de 21 de diciembre de 2012 (BOCG, Congreso de los Diputados, serie D, núm. 246, de 27 de marzo de 2013).

87 En inglés, "dry shore» (Sentencia Arbitral en el Caso del Beagle, http://legal.un.org/riaa/cases/ vol_XXI/53-264.pdf, párr. 98, p. 140); en alemán «trockene Küste» (http://dankenflex.com/kategorie/verschiedenes/thesis-fagalde.php); en holandés "droge kust»(http://kennisdoel.com/categories/onderwijs/thesis-fagalde.php); en danés «tør kyst»(http://clippel.com/kategorie/miscellany/speciale-fagalde.php).

${ }_{88}$ Kaldone, G. N., Frontera y Límite en su Marco Mundial: una Aproximación a la "fronterología", Caracas, Universidad Simón Bolívar, 1992, p. 48. 
derecho al uso equitativo y razonable de las aguas por un lado, y la norma convencional que establece el sistema de delimitación de la costa seca ha originado una controversia entre Costa Rica y Nicaragua» ${ }^{89}$.

Pedro Nikken señala que nada impide que los Estados «puedan establecer entre ellos cualquier tipo de delimitación, inclusive uno tan anormal como el de la "costa seca" ${ }^{90}$. Otros autores reconocen igualmente esta doctrina de la costa seca, como propuesta de solución para los problemas del Río de La Plata ${ }^{91}$ o para comprender uno de los problemas de delimitación de la costa entre Colombia y Venezuela ${ }^{92}$.

Otros autores, como el Prof. Jesús Verdú incluso la consideran como un mito $^{93}$. Supongo que con la expresión mito se refiere a la cuarta acepción de la palabra mito en el diccionario de la $\operatorname{RAE}^{94}$. Si esto es así, el Prof. Verdú no duda de la existencia de la doctrina de la costa seca, de lo que duda es de su aplicación al caso de Gibraltar. Ello debe ser por su apego a una única fuente, como serían los actos forzados a los que se ha visto abocada España, cuando esa no es ni la única fuente, ni siquiera la fuente en la que habría que basar la aplicación de esta doctrina al caso de Gibraltar, porque, en efecto, para poder modificar el principio general de que el territorio domina el mar, hay que basarse en normas convencionales o en la práctica seguida por los Estados en el caso concreto.

Es verdad que la actitud española ha sido en algunos momentos equívoca. El Real Decreto español de 10 de diciembre de 1876, calificado por José Luis Azcáraga como desafortunado ${ }^{95}$, hablaba de las aguas llamadas inglesas en Gibraltar, aunque a los únicos efectos de la persecución del contrabando «las comprendidas al Oeste, entre la falda del Peñón y la línea recta que partiendo de Punta Mala en dirección a Sierra Bullones, pasa a dos millas de Punta Europa, y al Sur y Este una extensión de tres millas contadas desde la playa en todas direcciones». Tengo que señalar de nuevo la expresión «a los únicos efectos de la persecución del contrabando».

No es menos verdad que este Real Decreto está hoy día derogado, de forma expresa, por el Decreto 2671 del Ministerio de Obras Públicas de 19 de

89 Querol, M., Estudio sobre los Convenios y Acuerdos de Cooperación entre los Países de América Latina y el Caribe, en relación con sistema hídricos y cuerpos de agua transfronterizo, Santiago de Chile, CEPAL, Naciones Unidas, Serie Recursos naturales e infraestructuras, 2003, núm. 64, p. 58.

90 Nikken, P., La «costa seca» favorece a Colombia, Bogotá, Colombia, Ministerio de Información y Turismo, 180, p. 11.

91 Véase, por ejemplo, MiLia, J. G., Geopolítica de Límites y Fronteras de la Argentina, Buenos Aires, Dunken, 2015, pp. 142-143.

92 Area, L. y Stockhausen, E. DE, El Golfo de Venezuela: documentación y cronología, vol. 3, Instituto de Estudios Políticos, Universidad Central de Venezuela, 2001, pp. 243, 307 y 436.

93 Verdú, J., op. cit., nota 5. Véase su propio título.

94 Persona o cosa a las que se atribuyen cualidades o excelencias que no tienen o bien una realidad de la que carecen.

95 Azcárraga Bustamante, J. L., «Las aguas españolas de Gibraltar (La Bahía de Algeciras a la luz del Derecho Internacional)», Sela SAmpIL (Libro Homenaje al Prof.), Estudios de Derecho Internacional Público y Privado, Universidad de Oviedo, 1970, p. 618. 
octubre de $1967^{96}$. Sin embargo, este nuevo Decreto lo que hace es confirmar un poco más la distribución jurisdiccional de las aguas de la Bahía. En efecto, dicho Decreto de 1967 determina la competencia territorial de la Junta de Obras y Servicios del Puerto de Algeciras con un trazado que responde a una delimitación equidistante prácticamente, respetando la zona que hasta el propio Derrotero de Costas español llama Fondeadero de los buques de guerra ingleses y Fondeadero prohibido ${ }^{97}$.

Un dato más sería la Orden de la Presidencia del Gobierno de 11 de abril de 1967 (BOE de 12 de abril de 1967) que estableció las prohibiciones de sobrevuelo en ciertas zonas de la Bahía de Algeciras ${ }^{98}$, coincidentes también con la línea divisoria media de dichas aguas ${ }^{99}$. Igualmente sucede con respecto al sector oriental del Peñón.

De hecho, la policía gibraltareña, con la ayuda británica guarda sus costas y establece sus reglas, no sólo respecto al tránsito marítimo o a los aspectos de seguridad, sino incluso en lo referente a sus recursos pesqueros ${ }^{100}$.

Sin embargo, esto podría referirse a la administración de las aguas no a su titularidad. En relación con la titularidad la consistencia de la actitud de España ha sido inequívoca, apelando, entre otros fundamentos, a la teoría de la costa seca.

Es indiferente si fue el régimen franquista el que «comenzó a esgrimir la teoría de la costa seca» ${ }^{101}$. Fue muy posterior cuando el Reino Unido empezó a reclamar espacios marítimos adyacentes a Gibraltar, más allá de las propias

96 BOE núm. 271, de 13 de noviembre de 1967.

97 Este Derrotero señala expresamente lo siguiente: «Fondeadero de los buques de guerra. Los buques de guerra ingleses fondean al S. de una línea que se extiende 6,6 cables en dirección 2701 a partir de un punto situado a 1,7 cables al 1731 de la luz del extremo N. del rompeolas.

El tenedero es bueno, mejor hacia fuera que hacia dentro, y no se debe fondear marcando el muelle de puerto Rosia a menos de 1201. Un buen sitio es en 45 metros a unos 3 cables al W. de la luz del muelle Sur, enfilando el ángulo NW del dique Norte con el extremo N. del rompeolas, que demorará al 0121 y la torre de las oficinas de los diques entre los depósitos de carbón del muelle Sur.

Fondeadero prohibido. Está prohibido fondear en una zona que se extiende 1,1 millas al W. de la Aeropista, y a corta distancia a cada lado de ella, estando en las cartas señalados los límites de esta zona. Tres boyas cónicas, pintadas a cuadros blancos y azules, se encuentran fondeadas muy juntas, en el N. del fondeadero prohibido, a unos 2, cables al N. de la cabeza del malecón marcado con la letra E, del dique Norte». Véase Derrotero de las Costas del Mediterráneo, núm. 3, t. I, del Instituto Hidrográfico de la Marina, 1982, pp. 58 y 59.

98 Estas prohibiciones no están hoy día en vigor. Las áreas prohibidas de sobrevuelo se encuentran en la Orden de 15 de marzo de 1985 (BOE de 1 de abril de 1985).

99 Esta línea divisoria media y las de prohibición de sobrevuelo pueden contemplarse en O’ReIlly, J. G., Gibraltar: Spanish and United Kingdom Claims Territory, Briefing núm. 4, Reino Unido, International Boundaries Research Unit, University of Durham, 1992, o también en el Briefing On the Occasion of the International Seminar On Boundary and territorial Issues in the Mediterranean Basin in an Age of Geopolitical Change, International Boundaries Research Unit, Foundation for International Studies, University of Malta, University of Durham, September 24th - 26th 1992.

100 Recientemente un tribunal gibraltareño ha considerado culpables de pescar ilegalmente en aguas gibraltareñas a cuatro marineros españoles, a los que les impuso una multa de 100 libras esterlinas a cada uno de ellos. Contrastar esta información en Europa Sur, 18 de mayo de 1996, p. 12.

101 Verdú BAEZA, J., La controversia sobre las aguas de Gibraltar..., op. cit., nota 5, p. 110. 
aguas interiores del Puerto de Gibraltar. De hecho, las «British Gibraltar Territorial Waters» son establecidas en 1987.

También es indiferente si se ejercen o no los derechos de soberanía en los espacios que se reclaman porque hay una evidente mala fe por parte de una Potencia colonial, considerándose lo que ya no es: soberana territorial, que impide el ejercicio del derecho. Hay una ocupación que debe cesar, por imperativo de Naciones Unidas, en la que el Reino Unido y España tienen que limitarse a negociar las fórmulas del rescate de la administración.

Por tanto, el hecho de que España no ejerza su derecho ${ }^{102}$ por imposibilidad «militar o policial» y para no tener que recurrir al uso de la fuerza, plantea su reclamación en el marco que le es posible, en el marco del Derecho. ¿Es imaginable qué ocurriría si España utilizara la fuerza para reclamar sus derechos? Fue el caso de Malvinas, de tan fausto recuerdo. La recuperación de un derecho no justifica el uso de la fuerza pero la imposibilidad del ejercicio de un derecho tampoco invalida el mismo.

Un Tribunal Arbitral como fue el que sentenció con su Laudo el conflicto del Beagle, entre Chile y Argentina ${ }^{103}$, estudió superficialmente la doctrina de la costa seca y consideró que su aplicación al caso no era aceptable ${ }^{104}$. Sin embargo, sí señaló que la doctrina de la costa seca podría aplicarse si mediaban normas convencionales que destruyeran el principio de que el territorio domina el mar, es decir, cabe el apoyo jurídico a esta doctrina, aunque no fuera aplicable al caso concreto que enjuiciaba el Tribunal Arbitral.

En la sentencia arbitral del Caso del Beagle se habla de "dry and sterile shore». El Tribunal Arbitral, por tanto, considera que, en algunos casos dados, esta teoría puede ser controvertida, es decir, no establece su inexistencia sino su inaplicabilidad al caso ${ }^{105}$.

Andrea Oelsner, en una perspectiva muy política, incluso simplona, la explica, en relación al Caso del Beagle, de la siguiente manera:

"The thesis of the "dry shore" for Argentina had long been demanded by some nationalistic sectors in Santiago, which understood that according to the 1881 Treaty "Argentine" sovereignty, in strict reality, goes only as far as to touch the Beagle Channel but not beyond; the Channel, its waters and its islands are Chilean in all their extensiveness» ${ }^{106}$.

102 La Prof. a González García critica esta inconsistencia española en relación con la práctica en la administración de las aguas adyacentes pero debería indicar cuál sería la alternativa. Véase GoNZÁLEZ García, I., «La Bahía de Algeciras y las aguas españolas», en DEl Valle Gálvez, A. y GonzÁlez García, I. (eds.), Gibraltar, 300 años, Universidad de Cádiz, 2004, p. 226.

${ }_{103}$ Laudo Arbitral de 2 de mayo de 1977 (http://legal.un.org/riaa/cases/vol_XXI/53-264.pdf).

104 Las palabras exactas que pronunció el Tribunal Arbitral en el párr. 107 del Laudo Arbitral al respecto fueron: "The Court considers it as amounting to an overriding general principle of law that, in absence of express provision to the contrary, an attribution of territory must ipso facto carry with it the waters appurtenant to the territory attributed».

105 http://legal.un.org/riaa/cases/vol_XXI/53-264.pdf, párr. 98, p. 140.

106 A. OelSner, International Relations in Latin American: Peace and Security in the Southern Cone, Nueva York y Londres, Routledge, 2005 (https://books.google.be/books?id=UexTAQAAQBAJ\&pg=PT138 
Por su parte, Rafael Escobar Santibáñez considera que «no puede estimarse o desestimarse, considerarse errónea o inconveniente una tesis que no existe como tal, ya que no se trata de deducciones más o menos ajustadas a la configuración geográfica regional, a las profundidades de la sonda o a divisorias de océanos, etc., como las demás tesis argentinas sobre el Beagle, sino simplemente de una interpretación literal de lo que expresa un documento internacional principal, el Tratado de Límites de 1881, interpretación que tiene la novedad de haber sido en su tiempo una primicia: ver lo que otros ojos no vieron [...] si la soberanía argentina llega solamente, en estricta realidad, de acuerdo con las disposiciones del Tratado, hasta tocar en el canal Beagle y no va más allá el canal, sus aguas y sus islas, son chilenas en toda su amplitud ${ }^{107}$.

El Prof. Álvarez señala también «y no se diga que hay anomalía en la doctrina que consagra el dominio de Chile sobre el canal Beagle por la circunstancia de encontrarse éste deslindante a dos países, puesto que, según los principios generales del Derecho internacional, cuando dos Estados delimitan en esa forma, el canal debe ser común; pues esta regla no tiene aplicación cuando, como en el presente caso, existe convención expresa sobre el particular, o uno de dichos Estados tiene a su favor la posesión inmemorial» ${ }^{108}$.

Por tanto, soy consciente de la controversia que ha despertado esta doctrina entre los internacionalistas pero igualmente soy consciente de que la misma ha servido para la delimitación de algunas fronteras y, sobre todo, la ha confirmado la Corte Internacional de Justicia, como una doctrina plenamente compatible con el Derecho internacional.

Un caso paradigmático ha sido llevado a cabo por el propio Reino Unido. Éste había ejercido autoridad y jurisdicción sobre una zona de "costa seca» en la Ocupación de Alemania tras la Segunda Guerra Mundial. Durante más de $27 \mathrm{~km}$ de costa, en la ría de Lübeck. El capitán de navío Ángel Liberal lo cuenta así:

«El mismo concepto de "costa seca" lo aplicaron los militares británicos y los soviéticos a lo largo de unos $27 \mathrm{~km}$ como frontera de sus respectivas Zonas de Ocupación (militares) de Alemania a partir de 1945, en el interior de la ría de Lübeck. La entrada de esta ría - que desemboca en el Báltico-junto con toda la orilla occidental, los primeros $6,4 \mathrm{~km}$ de la orilla oriental y toda la superficie del mar, pertenecientes a Schleswig-Holstein, quedaron en manos británicas. Los $27 \mathrm{~km}$ restantes de la orilla oriental, de Mecklemburgo-Pomerania Occidental, quedaron en manos soviéticas, sin jurisdicción alguna sobre el agua que bañaba la costa. Como vemos, la interpretación británica del principio de que «la tierra domina al mar» se modifica según varíen los intereses del Reino Unido y le permita su fuerza militar.

$\& l p g=P T 138 \& d q=\% 22 d r y+$ shore $\% 22+$ thesis \&source $=$ bl\&ots $=f 4 j O h F Q r 4 V \& s i g=W W C t W A L P c Q 0 e k c V \_d B$ $Y z w L v V 90 s \& h l=e s \& s a=X \& e i=F u w m V c i P H 8 f g a v S J g A N \& v e d=0 C B 8 Q 6 A E w A A \# v=$ onepage \& $q \& f=$ false $).$

107 Escobar Santibáñez, R., Los derechos de Chile en el Beagle, Santiago de Chile, Editorial Andrés Bello, 1969, p. 76.

108 Citado por ibid., p. 77. 
Esta "costa seca", años después, pasó a ser la frontera entre los dos Estados alemanes independientes y entre las dos Alianzas militares de las que formaban parte; a lo largo de ella se instalaron dispositivos como los del Muro de Berlín: alambradas, campos de minas, ametralladoras, perros, torretas de vigilancia, etc.» ${ }^{109}$.

Otro caso existente donde se aplica la teoría de la costa seca sería el de la Bahía de Cocinetas, entre Venezuela y Colombia, donde hay que recordar que el territorio colombiano llega hasta la orilla del mar y todas las aguas de la Bahía y la costa adyacente es venezolana. El Acta de Castilletes de 29 de abril de 1900, establecido por la Comisión Mixta Colombo-Venezolana, fijó las lindes de común acuerdo, en virtud del Tratado de 30 de diciembre de $1898^{110}$.

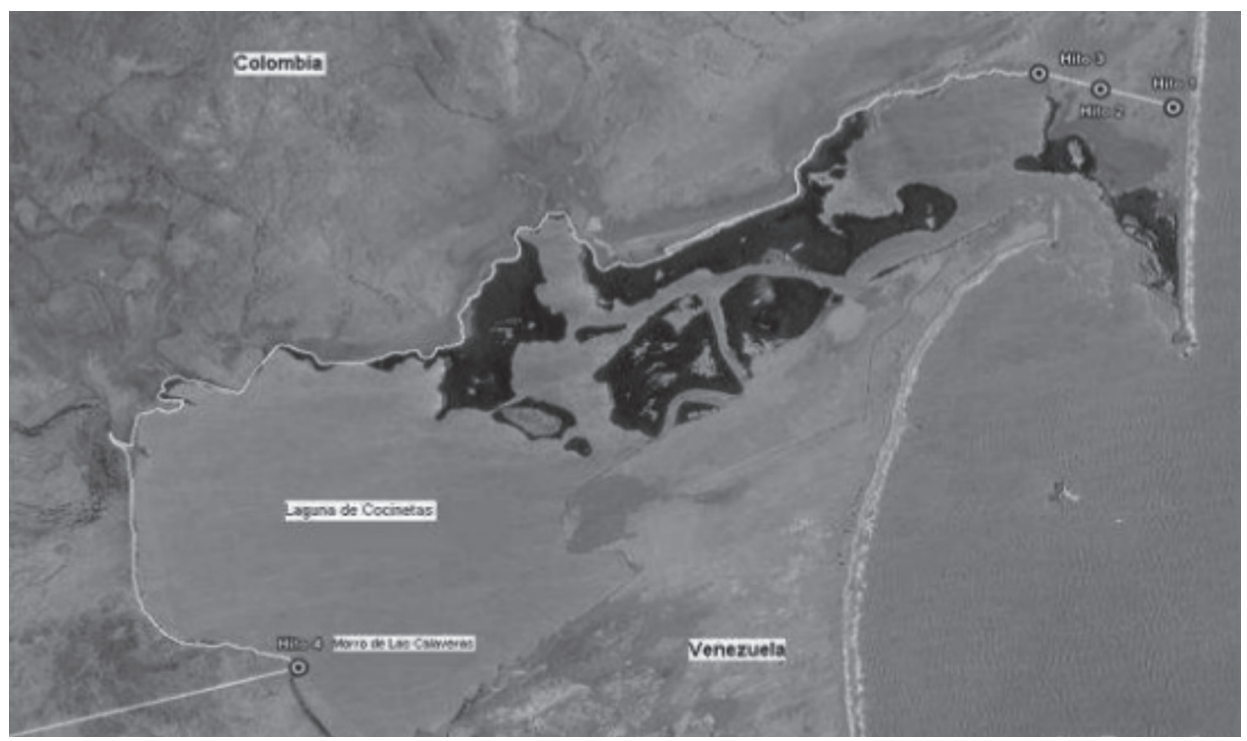

En relación con el Golfo de Venezuela ${ }^{111}$ hay más divergencias pero igualmente la doctrina de la costa seca está presente ${ }^{112}$. El Instituto de Estudios

109 Liberal, Á., "Gibraltar y su “costa seca” ", Ideal de Granada, 3 de octubre de 2014.

110 Esto fue declarado válido y en vigor por el Laudo Arbitral del Consejo Federal Suizo de 24 de marzo de 1922, en cuyo art. $2{ }^{\circ}$ se señala que «cada Parte podrá proceder a la ocupación definitiva de los territorios deslindados por los linderos naturales indicados por la Corona de España en su sentencia del 16 de marzo de 1891, y también por los linderos artificiales fijados de común acuerdo en 19001901, por la Comisión Mixta colombo-venezolana instituida en virtud del Pacto-Convención del 30 de diciembre de $1898 »$.

111 Para un análisis del conflicto, véase Olavarría de Tezanos Pinto, J., El Golfo de Venezuela es de Venezuela, Caracas, Armitano, 1988. También URdaneta, A., Problemas Fronterizos Colombo-Venezolanos, marzo de 2009 (http://www.monografias.com/trabajos-pdf2/problemas-fronterizos-colombo-venezolanos/problemas-fronterizos-colombo-venezolanos.pdf). Igualmente Vega AguIRRE, A. M., Análisis del Diferendo Jurídico y Político entre Colombia y Venezuela con Respecto al Dominio sobre el Golfo de Coquivacoa/de Venezuela y sus Límites Marítimos 1952-2010, Bogotá, Universidad Colegio Mayor de Nuestra Señora del Rosario, Facultad de Relaciones Internacionales, 2012 (http://repository.urosario.edu.co/ 
Fronterizos de Venezuela (IDEFV), en una nota publicada el 21 de abril de 2009, señala al Dr. Pedro José Lara Peña como el precursor de la teoría de la costa seca para el Golfo de Venezuela ${ }^{113}$. En este sentido, señala que Lara Peña «adoptó la tesis de costa seca para Colombia entre Castilletes y Punta Espada, de forma similar a la que ya existe desde el hito 3, hasta el hito 4 (morro de las Calaveras), o sea, la costa de la laguna de Cocinetas entre ambos puntos [...]. Por nuestra parte, el Instituto (IDEFV), sostiene que Colombia no posee ni un milímetro de costas en la Guajira más acá del mogote de los Frailes más próximo a Juyachí, que es el inicio de la frontera fijada por el Laudo de Madrid de 1891, el cual fue completamente desestimado en su Sección Primera por la Comisión Mixta demarcadora en 1900. Todo lo que allí se adoptó es nulo de toda nulidad, por lo que ambos países tienen la obligación de replantear esta Sección, en su totalidad (hasta el cerro Pintado), de acuerdo con el Laudo» ${ }^{114}$.

En realidad, Lara Peña llama a la tesis de la costa seca «Tesis de Condicionamiento Judicial del Título» ${ }^{115}$. Esta tesis no ha sido adoptada formalmente por el Gobierno venezolano ${ }^{116}$. Sin embargo, sí hay numerosos actos de origen interno que la avalan y, además, las tesis colombianas, para apoyar su reivindicación sobre parte de las aguas del Golfo de Venezuela, sí consideran que el archipiélago venezolano de las Islas Monjes no proyectan espacios marítimos y se trata de un enclave venezolano en aguas colombianas ${ }^{117}$, es decir, aplican la doctrina de la costa seca. Sin embargo, el archipiélago Los Monjes, en realidad son rocas o islotes, no islas y, por tanto, no generarían zona económica exclusiva pero sí mar territorial, acorde con la Convención de Naciones Unidas sobre el Derecho del Mar ${ }^{118}$.

En este sentido, Enrique Gaviria Liévano reconoce que hay voces oficiales venezolanas que reivindican la doctrina de la costa seca para su aplicación en el Golfo de Venezuela ${ }^{119}$. En este sentido no habría que olvidar que el Decreto venezolano de 16 de septiembre de 1939, en su art. 2 señala que:

bitstream/handle/10336/4131/1018424510-2012.pdf?sequence=3) y JURIS, K. y PEREIRA, M., La Política Exterior de Colombia y Venezuela frente a la Delimitación de Fronteras Marinas y Submarinas en el Golfo de Coquibacoa, Cartagena de Indias, Tesis de Grado Corporación Universitaria Rafael Núñez, 2007.

112 Otras soluciones pueden verse en Muñoz Miranda, L. H. y Vázouez Paternina, E. A., La Mediación de UNASUR como Alternativa Jurídico-Política para la Solución del Diferendo Limítrofe ColomboVenezolano por el Golfo de Coquibacoa/Venezuela, Cartagena de Indias, Universidad de Cartagena, 2014.

$113 \mathrm{Al}$ respecto, véase LARA PEÑA, P. J., Las tesis excluyentes de la soberanía colombiana en el Golfo de Venezuela, Caracas, Ex-Libris, 1988. Véase también LaRa Peña, P. J., El Golfo de Venezuela, Caracas, O. Ascanio Editores, 1998.

114 http://institutodeestudiosfronterizos 1.blogspot.com.es/2009/04/dr-pedro-jose-lara-pena-el-golfo-de. html.

115 Carta de Pedro José Lara Peña al Ministro de Defensa venezolano, José Vicente Rangel, el 20 de marzo de 2001 (http://institutodeestudiosfronterizos1.blogspot.com.es/2009/04/dr-pedro-jose-lara-pena-elgolfo-de_21.html), p. 4.

$116 \bar{h}$ ttp://rafael.bervin.over-blog.es/article-diferendo-limitrofe-del-golfo-de-venezuela-39512900.html.

117 Ibid.

118 Véase este reconocimiento también en Monroy CABra, M., El Diferendo Colombo-Venezolano, Bogotá, Editorial Oveja Negra, 1987, p. 89.

119 Gaviria Lievano, E., Derecho Internacional Público, Bogotá, Temis, 1988, p. 234. 
«En las bahías, golfos y senos sujetos a la exclusiva jurisdicción de la República, las aguas territoriales son el espacio marítimo que se extiende cinco kilómetros y 556 metros (tres millas náuticas) hacia el mar, medidos desde una línea recta trazada a través de la apertura».

Igualmente, la Nota de Protesta de la cancillería venezolana de 17 de junio de 1940 consideraría al Golfo de Venezuela como un "golfo histórico y sus aguas como nacionales» ${ }^{120}$. Obviamente hay quien considera también que «la tesis de la costa seca es una tontería, que no se le ocurre a nadie sensato y jamás se la oí a ningún dirigente venezolano serio» ${ }^{121}$.

Podríamos pensar que no son más que opiniones jurídicas, sin embargo, como reconoce Héctor Cuadra Moreno «la doctrina constituye una fuente preciosa, pero subsidiaria del Derecho internacional. La doctrina es considerada, según este artículo (se refiere al art. 38 del Estatuto de la CIJ) como un medio auxiliar para la determinación de las reglas de Derecho. Y así, la Corte funda su concepción de la nacionalidad, entre (otras) fuentes, en la «opinión de los autores» (Sentencia del 6 de abril de 1955, en el caso Nottebohm; Opi-

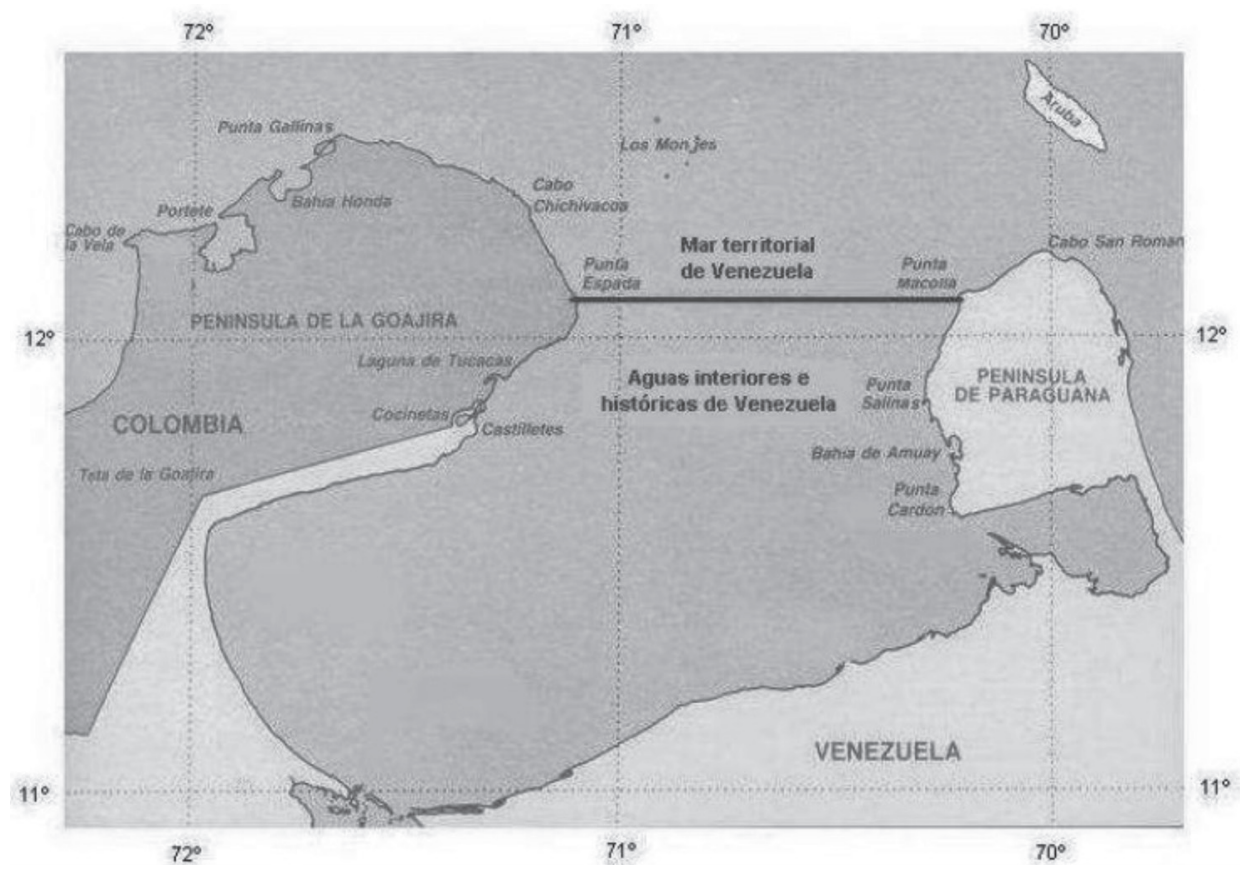

120 Ruano Montenegro, R., El Golfo de Venezuela. Aspectos Geopolíticos y Jurídicos (periodo 19221980), Caracas, Universidad Central de Venezuela, 2011, p. 20 (http://es.slideshare.net/geoeco2/el-golfode-venezuela-aspectos-geopolticos-y-jurdicos-perodo-19221980).

121 Zalamea, A., Catálogo de Errores: La Crisis Colombo-Venezolana, Bogotá, Editorial Oveja Negra, 1987, p. 45. 
nión del 21 de junio de 1971 en el caso de Namibia)» ${ }^{122}$. Al fin y al cabo es la forma de ir constituyendo la opinio iuris que es un elemento importantísimo en la conformación de las normas jurídicas internacionales ${ }^{123}$.

Otro caso útil para el análisis de la doctrina de la costa seca es el de las islas Likoma y Chizumulu, dentro del Lago Malawi, que están completamente rodeadas de aguas de Mozambique, aunque la parte terrestre pertenezca a Malawi ${ }^{124}$.

En este mismo lago, Malawi reivindica la soberanía sobre todas las aguas de la parte del lago que hace frontera con Tanzania, exigiendo la aplicación de la doctrina de la costa seca para Tanzania ${ }^{125}$. Los informes jurídicos, incluyendo uno de la antigua Presidenta de la Corte Internacional de Justicia, Rosalyn Higgins ${ }^{126}$, parecen todos ellos favorables a las tesis de Malawi, asentadas en un tratado internacional ${ }^{127}$ que le otorga estos espacios lacustres. Chris Mahony \& Otros consideran también que "The legality of the Lake dispute clearly supports Malawi» ${ }^{128}$. Cuando el Reino Unido unió la actual Tanzania (la antigua Tanganika alemana) a la Corona Británica, otorgó la administración al territorio de Nyasaland (actual Malawi) sin intervención alguna del territorio de Tanganika (actual Tanzania). Según James Mayall, durante los Informes Anuales Británicos desde 1924 hasta 1932 siempre se refirieron a la línea media de la frontera del lago ${ }^{129}$. Sin embargo, desde 1935 los informes británicos se referían siempre, incluyendo los mapas, a la frontera a lo largo de la costa ${ }^{130}$.

122 Cuadra Moreno, H., «La contribución de la jurisprudencia de la Corte Internacional al Derecho Internacional», Revista Mexicana de Derecho Comparado, vol. 15, 1972, pp. 447-448.

123 Toledo TAPiA, F. E., "La opinio iuris como elemento psicológico de la costumbre», Revista Chilena de Derecho, vol. 17, 1990, pp. 483-508.

${ }^{124}$ La base de esta situación se encuentra en los tratados internacionales celebrados por Gran Bretaña y Portugal, potencias coloniales precedentes de ambos Estados, a finales del siglo XIX y que, en base el principio del uttis possidetis iuris han aplicado los nuevos Estados. Véase Department of StATE, Malawi-Mozambique Boundary, International Boundary Study, núm. 112, Washington, Bureau of Intelligence and Research, 1971, p. 4.

125 Las partes han llegado al acuerdo de someter esta disputa territorial a la Corte Internacional de Justicia (http://www.tvcnews.tv/?q=article/malawi-tanzania-agree-icj-over-lake-dispute).

126 "While the boundary between Malawi and Tanzania is Lake Nyasa [Malawi and] is a complicated issue, and not without its difficulties, I feel that the legal claims of Malawi to all of Lake Nyasa, and the submerged lands there under, is considerably the better claim». Véase http://mabvutojobani. com/2013/07/20/uk-top-judge-backed-malawi-in-lake-dispute/.

127 Anglo-German Treaty (Heligoland-Zanzibar Treaty), July 1, 1890 (http://germanhistorydocs.ghidc.org/pdfleng/606_Anglo-German\%20Treaty_110.pdf). Un estudio histórico sobre este Tratado puede verse en Niler Pyeatt, D., Heligoland and the Making of the Anglo-German Colonial Agreemnt in 1890, Texas Tech University, 1988 (http://repositories.tdl.org/ttu-ir/bitstream/handle/2346/12379/31295000269471. pdf? sequence $=1$ ).

128 Véase Mahony, C. et al., Where Politics Borders Law: The Malawi-Tanzania Boundary Dispute, Working paper núm. 21 del New Zealand Center for Human Rights Law, Policy and Practice, February 2014, p. 16 (https://cdn.auckland.ac.nz/assets/humanrights/Research/MalawiTanzania-NZCHRLPPfinal.pdf).

129 MaYall, J., "The Malawi-Tanzania Boundary Dispute», The Journal of Modern African Studies, vol. 11, 1973, núm. 4, p. 624.

130 Mahony, C. et al., op. cit., nota 128, p. 3. 
Recientemente Tanzania ha rehuido del reconocimiento del Tratado Heligoland de 1890 que hasta ahora también aceptaba ${ }^{131}$. Quizás, considerando sus posiciones débiles, ha optado por esta nueva estrategia.

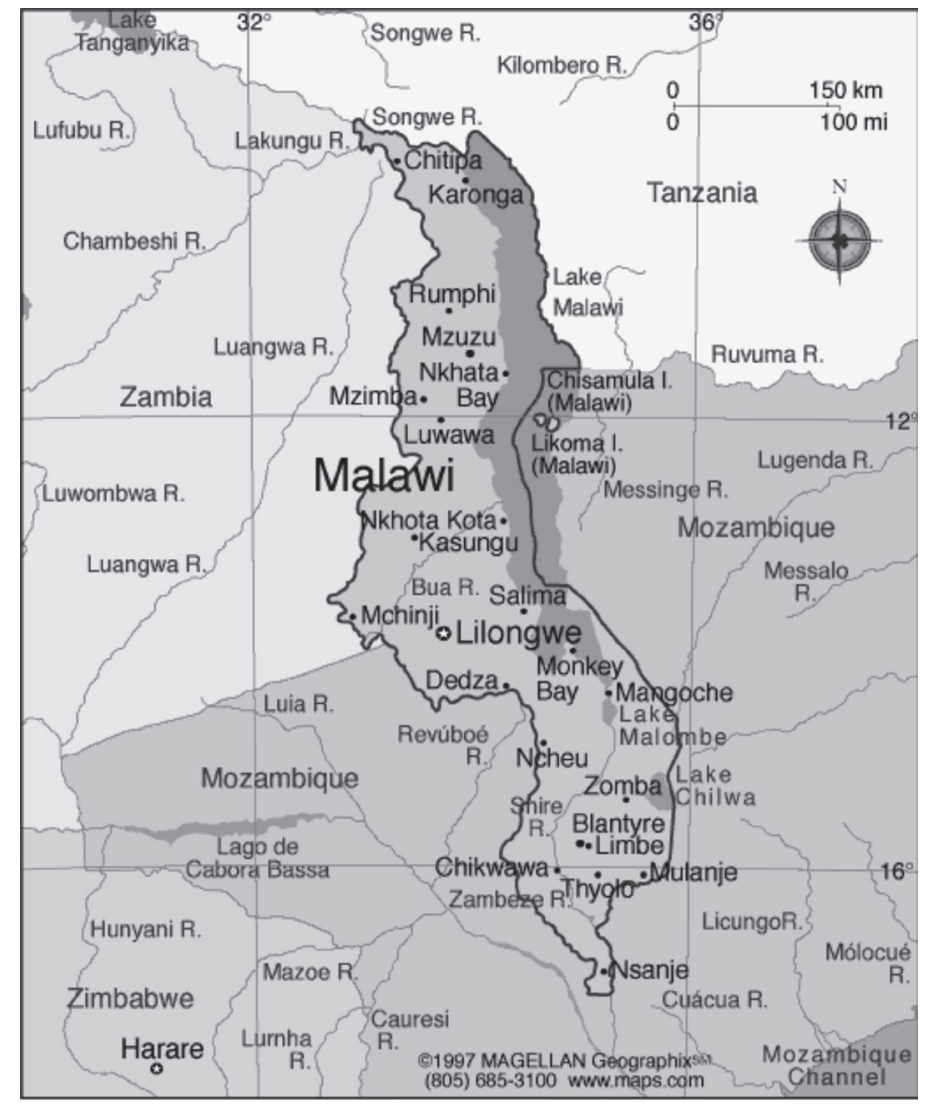

Sin embargo, lo que apoya definitivamente la autoridad de la aplicación de la doctrina de la costa seca son los pronunciamientos de la Corte Internacional de Justicia quien ha tenido la oportunidad de analizar esta doctrina y decidir sobre su aplicación en dos casos: el caso de Costa Rica contra Nicaragua ${ }^{132}$ y el caso de Chile contra Perú ${ }^{133}$.

En el caso de Costa Rica contra Nicaragua, en el Río San Juan, ambas Partes aceptan la existencia de un Tratado Internacional ${ }^{134}$ que reconoce la

131 Lalbahadur, A., "Malawi vs. Tanzania vs. SADC: Regional Dispute Resolution Bites the Dust», South Africa Institute of International Affairs, 13 August 2013 (http://www.saiia.org.za).

132 Sentencia CIJ, caso Dispute Regarding Navigational and Related Rights (Costa Rica v. Nicaragua), de 13 de julio de 2009.

133 Sentencia CIJ, caso Maritime Dispute (Perú v. Chile), de 27 de enero de 2014.

134 El Tratado de Límites Jerez Cañas de 15 de abril de 1858. 
soberanía de la masa de agua del Río San Juan a Nicaragua, aunque otorga también limitaciones a esa soberanía en el sentido de que ofrece el Derecho de navegación y de pesca de subsistencia a Costa Rica ${ }^{135}$. Por tanto, el límite entre ambos Estados está en la orilla del Río San Juan que linda con Costa Rica. Es pura aplicación de la doctrina de la costa seca.

La Corte Internacional de Justicia señala textualmente que

«los gobiernos de Costa Rica y Nicaragua llegaron a un acuerdo el 15 de abril de 1858 mediante un Tratado de Límites, el cual fue ratificado por Costa Rica el 16 de abril de 1858 y por Nicaragua el 26 de abril de 1858. El Tratado de Límites de 1858 fijó el trazado de la frontera entre Costa Rica y Nicaragua desde el océano Pacífico hasta el mar Caribe. De acuerdo con la frontera entonces trazada, el Distrito de Nicoya se encontraba en el territorio de Costa Rica. Entre un punto tres millas inglesas del Castillo Viejo y el mar Caribe, el Tratado fijó la frontera a lo largo de la margen derecha del río San Juan. Establecía el dominio y jurisdicción soberanos de Nicaragua sobre las aguas del río San Juan, pero al mismo tiempo afirmaba los derechos de navegación de Costa Rica "con objetos de comercio" en la parte baja del curso del río» ${ }^{136}$.

En realidad Costa Rica no objetaba la titularidad jurídica nicaragüense de las aguas del río San Juan, en su conjunto, incluyendo las aguas que bañaban sus propias costas. Objetaba los límites impuestos por Nicaragua al Derecho de navegación costarricense.

\section{COSTA RICA - NICARAGUA}

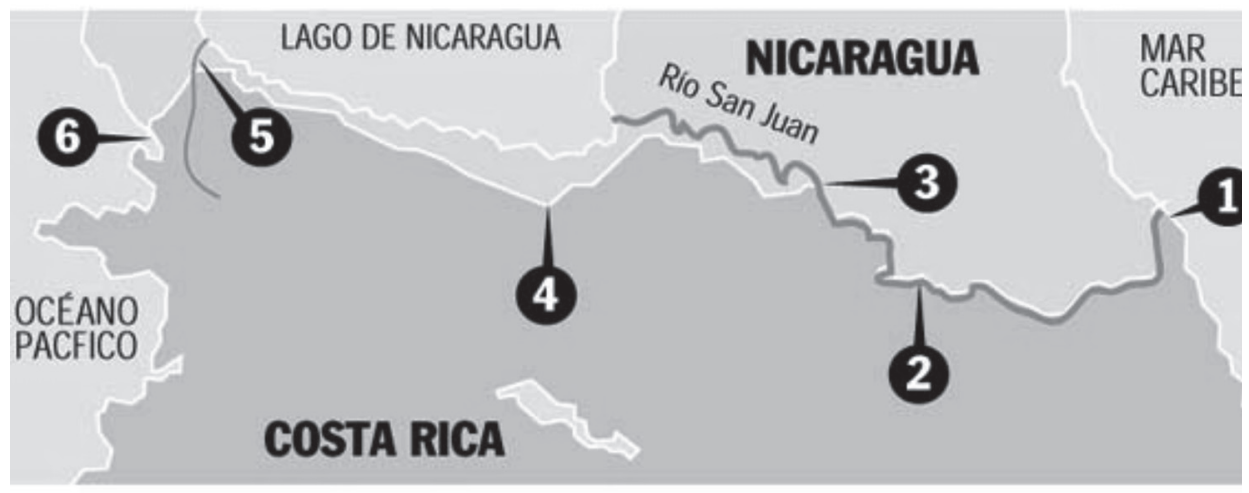

\section{PUNTOS DE REFERENCIA}

1. Punta Castilla.

2. Margen del río San Juan
3. Castillo Viejo

4. 2 millas del Lago de Nicaragua
5. Rio Sapoá

6. Bahía Salinas

135 El Tratado reconoce el «dominio y sumo imperio» nicaragüense sobre todo el río San Juan. Y concede, en un tramo del río de $140 \mathrm{~km}$ «derechos perpetuos» de libre navegación con objeto de comercio. Véase Sentencia CIJ caso Dispute Regarding Navigational and Related Rights (Costa Rica $v$. Nicaragua), de 13 de julio de 2009, párr. 43, que reproduce el art. VI del Tratado.

136 Una traducción oficiosa de la sentencia se puede obtener en ACDI, Bogotá, ISSN: 2027-1131/ ISSNe: 2145-4493, vol. 3, 2010, pp. 7-411, párr. 19. 
En el caso de Chile contra Perú, la Corte Internacional de Justicia adjudica los espacios marítimos de una franja costera, perteneciente a Perú, entre Punta Concordia ${ }^{137}$ y el Paralelo Geográfico del Hito núm. $1^{138}$, a 264,50 metros hacia dentro de tierra, aceptado por las partes como punto de delimitación marítima. Tiene una longitud de casi 300 metros y se le otorga a Chile, dejando esa parte del territorio peruano sin acceso al mar, que desde la orilla pertenece a Chile ${ }^{139}$.

Entre Punta Concordia y el punto en que se produce una intersección entre el paralelo geográfico y la orilla del mar, trazado desde el Hito núm. 1, se produce una "costa seca», de 323 metros, cuyas aguas son chilenas y cuya tierra es peruana.

Chile ha argumentado ante la Corte Internacional de Justicia que la frontera chileno-peruana estaba en el Hito núm. 1, a pesar de la existencia del Tratado de Lima de 1929, exigiendo que el límite marítimo comience en el Hito núm. 1, en base al Convenio Especial sobre Zona Marítima de 4 de diciembre de $1954^{140}$, que establecía los límites marítimos. El Tratado de Lima de 1929 establecía claramente los límites terrestre ${ }^{141}$ y ello ha sido mencionado de forma expresa por la Corte Internacional de Justicia. Igualmente,

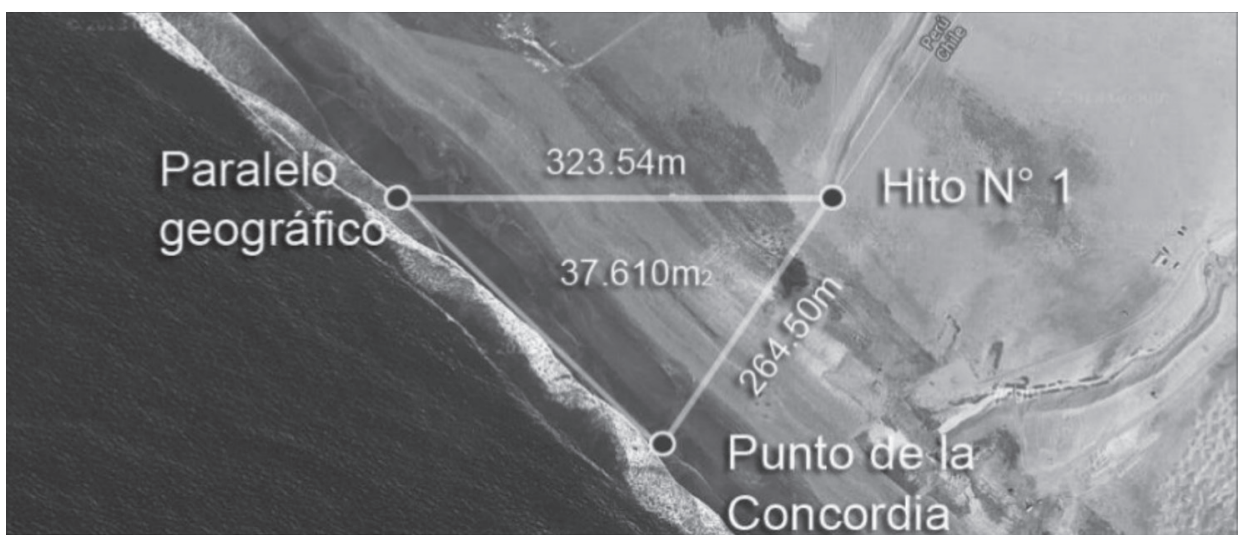

137 El Tratado entre Chile y Perú de 3 de junio de 1929, conocido como Tratado de Lima, determina que el punto fronterizo terrestre entre ambos Estados es Punta Concordia. Véase en http://www. historia.uchile.cl/CDA/fh_article/0,1389,SCID\%253D15754\%2526ISID\%253D563\%2526PRT\%253D157 47\%2526JNID\%253D12,00.html.

138 Dado que en Punta Concordia no podía establecer un Faro, Hito o Poste, se puso 270 metros hacia adentro.

139 Sentencia CIJ caso Maritime Dispute (Perú c. Chile), de 27 de enero de 2014, párr. 176. Un interesante análisis al respecto puede verse en ConRoY, H. W., «El punto Concordia y el inicio de la frontera marítima entre el Perú y Chile», Agenda Internacional, vol. 21, 2014, núm. 32, pp. 51-78.

140 Véase el texto en http://www.historia.uchile.cl/CDA/fh_article/0,1389,SCID\%253D15766\%2526I SID\%253D563\%2526PRT\%253D15747\%2526JNID\%253D12,00.html.

141 Art. 2 del Tratado de Lima de 1929: «La línea divisoria entre dichas dos partes (Tacna-Arica) y en consecuencia la frontera de los territorios del Perú y Chile partirá de un punto en la costa que se denominará Concordia, distante $10 \mathrm{~km}$ al norte del puente del río Lluta para seguir hacia el oriente...». 
Punta Concordia fue señalada por la Comisión Demarcadora de Límites de 1929-1930 como frontera terrestre.

Por tanto, es difícil argumentar que la doctrina de la costa seca no existe porque hay evidencias empíricas de su aplicación y una rica práctica, a pesar de su excepcionalidad.

\section{CONCLUSIONES}

1. El Derecho internacional sobre descolonización impide que se puedan atribuir espacios para su administración a las potencias coloniales, sobre todo si Naciones Unidas, garante del ejercicio de este derecho, toma la decisión de considerar que un territorio sometido a dominación colonial debe integrarse al territorio circunvecino de otro Estado porque la población no puede decidir el destino del territorio, por no ser la legítima titular del derecho de autodeterminación.

2. España y el Reino Unido reconocen la vigencia del Tratado de Utrecht a los efectos de legitimar la presencia del Reino Unido en la ocupación de Gibraltar. Por ello, le corresponde, hasta tanto se proceda a su reintegración, la administración colonial del puerto de Gibraltar. Este puerto dispone, como todos los puertos, de aguas interiores, de espacio jurídico-marítimo que le reconoce el actual Derecho del Mar. Para ello, España debe facilitar el acceso y la salida de los buques con destino o con procedencia hacia o desde Gibraltar, aunque esto suponga atravesar su mar territorial. Tal como le reconoce el Derecho internacional del Mar, el ejercicio del derecho de paso inocente tiene los límites establecidos en los reglamentos de prevención medioambiental, seguridad nacional, ejercicio de control del contrabando, etc. En cuanto a los buques de guerra u otros buques de Estado podrán ejercer el derecho de paso inocente siempre y cuando no supongan un peligro para el Estado cuyo mar territorial estén atravesando.

3. El Derecho internacional del Mar no es el único corpus iuris aplicable a las aguas marítimas adyacentes a Gibraltar. Este derecho puede ser modificado por un derecho excluyente como la norma imperativa sobre descolonización, por un derecho preexistente o por un derecho convencional especial que limite los derechos del Estado costero. Nada impide que existan tratados internacionales que limiten e incluso impidan el ejercicio del Derecho del Mar. El Tratado de Utrecht es una norma especial que deroga la norma general. Por tanto, aplicado al caso de las aguas marítimas adyacentes a Gibraltar, está limitando el ejercicio del actual Derecho del Mar por parte del Reino Unido exclusivamente a las aguas interiores del puerto de Gibraltar y al derecho de acceso y salida de los buques desde o hacia su puerto, a través del mar territorial español.

4. El principio general mediante el cual «el territorio domina el mar» puede ser derogado por un tratado internacional o por el ejercicio de la práctica de los Estados. En estos casos, la doctrina de la costa seca es plenamente 
aplicable si existen normas convencionales, como existen en el caso de Gibraltar. Hay práctica de los Estados al respecto e incluso pronunciamientos judiciales de la Corte Internacional de Justicia que lo avalan.

\section{RESUMEN}

\section{LA CONTROVERSIA SOBRE LA TITULARIDAD JURÍDICO-INTERNACIONAL DE LOS ESPACIOS MARÍTIMOS ADYACENTES A GIBRALTAR}

Este estudio tiene por objetivo identificar el Derecho aplicable en relación a la titularidad de las aguas marinas adyacentes a Gibraltar. Para ello el autor tiene en cuenta cuatro elementos: la situación colonial específica, donde la Organización de las Naciones Unidas viene señalando, de forma ininterrumpida la necesidad de establecer negociaciones entre la Potencia Administradora (Reino Unido) y España para proceder a la reintegración territorial de Gibraltar a España, teniendo en cuenta los intereses y aspiraciones legítimos acordes con el Derecho internacional de la población de Gibraltar. Igualmente analiza la cesión del puerto de Gibraltar al Reino Unido, quien en la actualidad lo administra, incluyendo sus aguas interiores. También se analiza la aplicación del principio lex specialis derogat legi generali, considerando el Tratado de Utrecht como lex specialis y al Derecho del Mar como lex generalis, así como la aplicación de teoría de la «costa seca» al caso concreto de Gibraltar.

Palabras clave: Bahía de Algeciras, Gibraltar, costa seca, colonización.

\section{ABSTRACT \\ THE CONTROVERSY SURROUNDING THE SOVEREIGN TITLE OF GIBRALTAR'S ADJACENT MARINE WATERS IN INTERNATIONAL LAW}

This study seeks to identify the applicable law relating to the sovereign title of Gibraltar's adjacent marine waters. To this end, the author considers four elements. The first element relates to the specific colonial situation where the United Nations have been continuously outlining the need for negotiations between the Administrator Power (UK) and Spain to proceed to the reintegration of Gibraltar into the Spanish territory, taking into account the interests and legitimate aspirations of the population of Gibraltar which are consistent with International Law. It also analyzes the cessions of the port of Gibraltar to the UK, which currently manages the port and its internal waters. The principle of lex specialis derogat legi generali is also analyzed, where the Treaty of Utrecht is considered as lex specialis and the Law of the Sea as lex generalis and, finally, the application of the "dry shore» theory to the specific case of Gibraltar.

Keywords: Bay of Algeciras, Gibraltar, «dry shore», colonization.

\section{RÉSUMÉ \\ LA CONTROVERSE SUR LA SOUVERAINETÉ EN DROIT INTERNATIONAL DES ESPACES MARITIMES ADJACENTS À GIBRALTAR}

Cette étude vise à identifier le droit applicable en matière de souveraineté des eaux marines adjacentes à Gibraltar. A cette fin, l'auteur considère quatre éléments. En premier lieu, la situation coloniale spécifique, au regard de laquelle les Nations Unies ont toujours 
souligné la nécessité de négociations entre la Puissance administrant (le Royaume-Uni) et l'Espagne en vue de procéder à la réintégration territoriale de Gibraltar à l'Espagne, en tenant compte des intérêts et des aspirations légitimes, conformément au droit international, de la population de Gibraltar. L'étude analyse également la cession du port de Gibraltar au Royaume-Uni, qui le gère actuellement, y compris ses eaux intérieures. Sont également analysés le principe lex specialis derogat legi generali, en tenant en compte le fait que la lex specialis est le Traité d'Utrecht et la lex generalis le droit de la mer, ainsi que l'application de la théorie de la «côte sèche» au cas de Gibraltar.

Mots-clés: Baie d'Algésiras, Gibraltar, côte sèche, colonisation. 